\author{
Monograph \\ urn:1sid:zoobank.org:pub:E3ED109B-70C8-414D-A245-6E3590C9E5B5
}

\title{
New species of Philopterus Nitzsch, 1818 (Ischnocera: Philopteridae), with notes on Cypseloecus Conci, 1941
}

\author{
Daniel R. GUSTAFSSON ${ }^{\circledR 1, *}$, Tomas NAJER ${ }^{\circledR 2}$, Fasheng ZOU ${ }^{\circledR 3}$ \& Sarah E. BUSH ${ }^{\circledR 4}$ \\ ${ }^{1,3}$ Guangdong Key Laboratory of Animal Conservation and Resources, \\ Guangdong Public Laboratory of Wild Animal Conservation and Utilization, \\ Institute of Zoology, Guangdong Academy of Sciences, 105 Xingang West Road, \\ Haizhu District, Guangzhou 510260, China. \\ ${ }^{2}$ Department of Veterinary Sciences, Faculty of Agriculture, Food and Natural Resources, \\ Czech University of Life Sciences, Kamycka 129, 16500 Prague 6, Czech Republic. \\ ${ }^{4}$ School of Biological Sciences, University of Utah, 257 S. 1400 E., \\ Salt Lake City, Utah 84112, USA. \\ *Corresponding author: kotatsu@fripost.org \\ 2Email: najer@af.czu.cz; tomas.najer@gmail.com \\ ${ }^{3}$ Email: zoufs@giabr.gd.cn \\ ${ }^{4}$ Email: dovelouse@gmail.com

\footnotetext{
${ }^{1}$ urn:1sid:zoobank.org:author:8D918E7D-07D5-49F4-A8D2-85682F00200C

${ }^{2}$ urn:1sid:zoobank.org:author:08A25BDD-8CCD-4709-9A57-7CE235D473C7

${ }^{3}$ urn:1sid:zoobank.org:author:A0E4F4A7-CF40-4524-AAAE-60D0AD845479

${ }^{4}$ urn:lsid:zoobank.org:author:87DAE296-C04F-4DA5-82A9-AC2715A065F8
}

\begin{abstract}
We describe and illustrate eight new species of chewing lice in the genus Philopterus Nitzsch, 1818, parasitic on hosts in the bird families Cardinalidae, Chloropseidae, Hirundinidae, Icteridae, Motacillidae, Paridae, and Vangidae from China, Peru, South Africa, Thailand, and the USA. They are: Philopterus coriaceus sp. nov. from Molothrus oryzivorus oryzivorus (Gmelin, 1788); P. hebes sp. nov. from Chloropsis aurifrons inornata Kloss, 1918 and C. cochinchinensis kinneari Hall \& Deignan, 1956; P. micropunctatus sp. nov. from Anthus hodgsoni Richmond, 1907; P. afropari sp. nov. from Melaniparus cinerascens cinerascens (Vieillot, 1818); P. pseudhirundo sp. nov. from Pseudhirundo griseopyga Sundevall, 1850; P. sinensis sp. nov. from Hemipus picatus capitalis (Horsfield, 1840); P. stansburyensis sp. nov. from Pheucticus melanocephalus melanocephalus (Swainson, 1827); and P. trepostephanus sp. nov. from Tephrodornis virgatus fretensis Robinson \& Kloss, 1920 and T. v. mekongensis Meyer de Schauensee, 1946. Philopterus hebes sp. nov. constitutes the first record of the genus Philopterus from the Chloropseidae. We also provide some notes on the morphology and status of Cypseloecus Conci, 1941.
\end{abstract}

Keywords. Phthiraptera, Philopteridae, Philopterus, Cypseloecus, new species.

Gustafsson D.R., Najer T., Zou F. \& Bush S.E. 2022. New species of Philopterus Nitzsch, 1818 (Ischnocera: Philopteridae), with notes on Cypseloecus Conci, 1941. European Journal of Taxonomy 790: 1-52. https://doi.org/10.5852/ejt.2022.790.1641 


\section{Introduction}

The Philopterus complex (Phthiraptera: Ischnocera) comprises several genera of chewing lice, all of which appear to be 'head louse' ecomorphs (Johnson et al. 2012). The majority of the species parasitize songbirds (Passeriformes), but a small number of species parasitize hosts in the orders Coraciiformes, Galbuliformes, and Trogoniformes (Mey 2004; Gustafsson et al. 2019). The complex contains 224 species, of which 193 are currently placed in the genus Philopterus Nitzsch, 1818 sensu Mey 2004 (Price et al. 2003; Mey 2004; Valim 2006; Cicchino 2007; Sychra et al. 2010, 2011; Najer et al. 2012a, 2012b, 2016, 2020a; Valim \& Palma 2013; Gustafsson \& Bush 2014, 2017; Gustafsson et al. 2019).

Comparatively little work has been done to elucidate the relationships of lice within the genus Philopterus. In the most comprehensive treatment thus far, Złotorzycka (1964) and Złotorzycka \& Lucińska $(1975,1976)$ separated groups based largely on host associations; they considered the genus Philopterus to be limited to the species parasitizing corvid hosts (Corvidae), and the genus Cypseloecus Conci, 1941 was limited to species parasitizing swallows (Hirundinidae). All other species were placed in the genus Docophorulus Eichler, 1944. Złotorzycka \& Lucińska $(1975,1976)$ further divided both Philopterus and Docophorulus into species groups; however, these treatments only considered European species, and thus do not cover the vast majority of the diversity of this near-global group. Moreover, the morphological characters that underpin the Złotorzycka-Lucińska $(1975,1976)$ classification are often of dubious usefulness, which is exacerbated by the fact that few other detailed descriptions and illustrations of these species have been published. In most cases, comparisons with type specimens are necessary for identification of the species included in this classification system.

Hopkins \& Clay (1952) and Price et al. (2003) considered most proposed genera in this group to be synonymous with Philopterus. However, Mey (2004) resurrected several genera based on morphological arguments, and described several new genera in the complex. Moreover, recent genetic data suggest that the genus Philopterus, as currently circumscribed, is paraphyletic (Najer et al. 2020b), with the genera Tyranniphilopterus Mey, 2004 and Philopteroides Mey, 2004 possibly nested inside Philopterus.

A thorough revision of the Philopterus complex based on morphological and genetic data is sorely needed. Such an undertaking is beyond the scope of this study; however, we identify, describe and illustrate several morphological characters that are likely to prove useful in understanding relationships among taxa in the complex. For example, the structure of the mesosome is highly variable between species, suggesting that male genital characters may be useful for finding and delimiting species groups within the genus. In contrast, most somatic and setal characters of the species in Philopterus are quite conserved, which may indicate evolutionary relationships among more distantly related species (see below).

Here we describe eight new species of Philopterus belonging to different groups within this genus. For all species, we have made a special effort to describe and illustrate key morphological characteristics to facilitate identification, and to lay a solid taxonomic foundation that can be used in the future formation of species groups within the genus Philopterus. We do not propose any new species groups here, but we note that the species parasitizing swallows are morphologically distinct and the genus Cypseloecus should be resurrected, either as a subgenus of Philopterus or as a separate genus.

\section{Material and methods}

Slide-mounted specimens were examined with Nikon Eclipse E600 and Nikon Eclipse TI-E light microscopes (Nikon, Tokyo, Japan). Illustrations were made through the same microscopes, fitted with a drawing tube or Andor Clara camera (Oxon, United Kingdom), then collated and edited in GIMP (www.gimp.org) and NIS Elements 4.50.00 LO (Nikon, Tokyo, Japan) using an Intuos 3 PTZ-1230 tablet (Wacom, China). Measurements were made from photos taken with the same microscope with 
an Olympus DP25 camera and digital measuring software (ImageJ ver. 1.48, Wayne Rasband). All measurements are given in millimetres, as ranges (mean value, when $\mathrm{n} \geq 10$ ). Dimensions taken and abbreviations thereof follow Najer et al. (2016), and include:

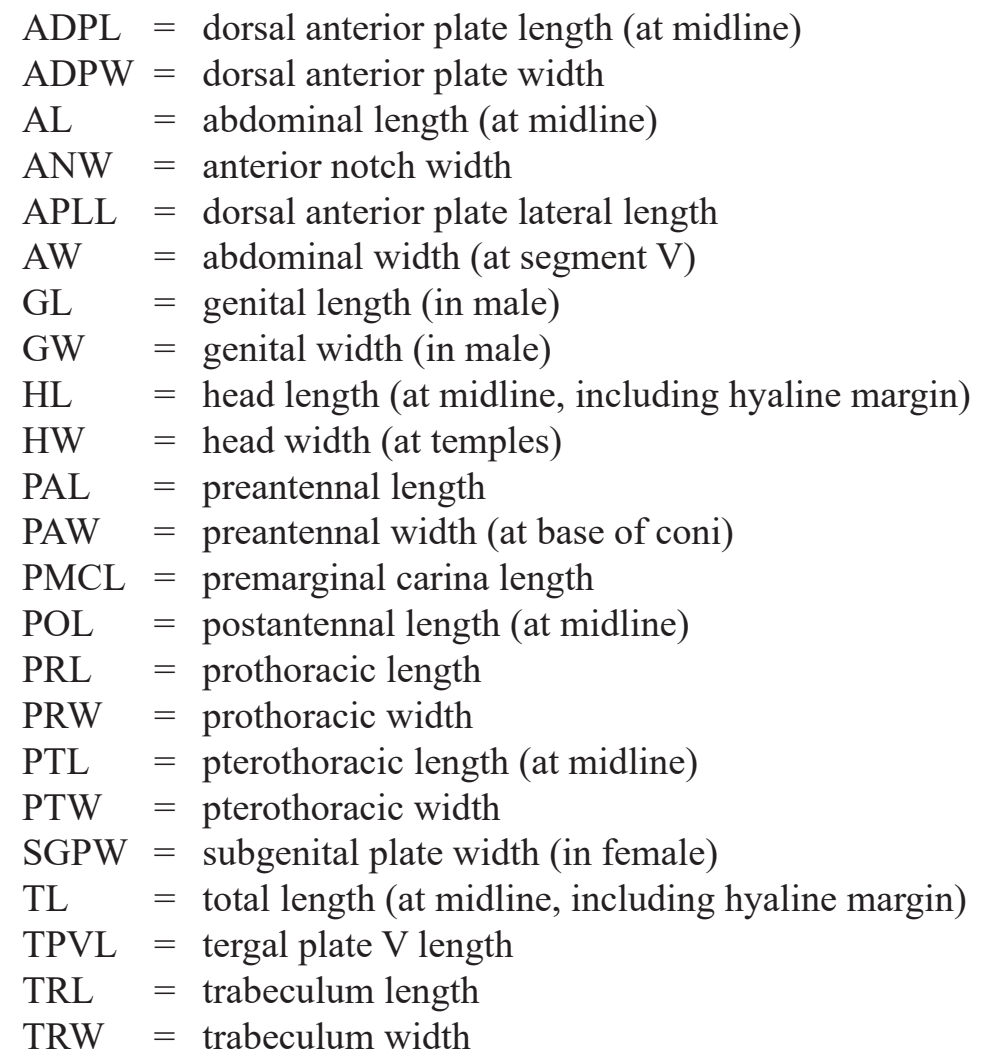

Morphological and setal terms and their abbreviations follow Clay (1951), Mey (1994), Najer et al. (2016), and Gustafsson \& Bush (2017). Names for setal characters are given in italics, whereas abbreviations for structural characters are given in upper-case. Tergal, pleural, and sternal setae were counted on each side separately, and counts given here denote setae on one side only; these normally differ between the sides of the same specimen as well as between specimens. Note that the trichobothria and thorn-like setae of the pterothorax and trichobothria of abdominal segment VIII of both sexes are not included in the setal counts, as these are constant throughout the Philopterus complex. For clarity, some pleural setae were illustrated on the dorsal side; however, as the lateral margins of the abdomen are typically non-sclerotized, the exact location of these setae depends on the position of the mounted specimen. In some cases, single pleural setae are situated on the postero-lateral corner of the tergopleurite or in an unsclerotized invagination of this corner. Abbreviations for setal characters follow Gustafsson \& Bush (2017) and include:

$$
\begin{aligned}
a d s & =\text { anterior dorsal seta } \\
\text { as } 1-3 & =\text { anterior setae } 1-3 \\
\text { avs } 1-3 & =\text { anterior ventral setae } 1-3 \\
d s m s & =\text { dorsal submarginal seta } \\
m d s & =\text { mandibular seta } \\
m t s 1-5 & =\text { marginal temporal setae } 1-5 \\
o s & =\text { ocular seta } \\
\text { pas } & =\text { preantennal seta } \\
\text { pcs } & =\text { preconal seta } \\
\text { pos } & =\text { preocular seta }
\end{aligned}
$$


pts $\quad=$ posttemporal seta

s1-4 = sensilla $1-4$

vsms $1-2=$ ventral submarginal setae $1-2$

Head setae discussed in the text are indicated in Fig. 3.

Host taxonomy follows Clements et al. (2019).

All specimens are deposited at the following institutions:

MFN = Museum für Naturkunde, Berlin, Germany

NHMUK $=$ Natural History Museum, London, UK

PIPR = Price Institute for Parasite Research, University of Utah, Salt Lake City, USA

USNM = National Museum of Natural History, Smithsonian Institution, Washington, D.C., USA

Order Phthiraptera Haeckel, 1896

Superfamily Ischnocera Kellogg, 1896

Family Philopteridae Burmeister, 1838

Philopterus complex

Genus Philopterus Nitzsch, 1818

Philopterus Nitzsch, 1818: 288.

Docophorus Nitzsch, 1818: 289 (in partim).

Cypseloecus Conci, 1941: 126.

Debeauxoecus Conci, 1941: 126.

Docophorulus Eichler, 1944: 80.

Bitrabeculus Uchida, 1948: 317.

Prunellides Złotorzycka \& Eichler, 1984: 219, figs 1-3.

\section{Type species}

Pediculus ocellatus Scopoli, 1763, ex Corvus corone Linnaeus, 1758, by subsequent designation (Neumann 1906).

\section{Geographical distribution}

As currently circumscribed (Mey 2004), likely global apart from Antarctica, but poorly known in the Southern Hemisphere.

\section{Host associations}

As currently circumscribed (Mey 2004), widely distributed across hosts in the Passeriformes. A single species (Philopterus solus Tendeiro, 1962) has been described from a bucerotiform host, but Mey (2004: 200) doubted the authenticity of this record.

\section{Remarks}

All species described herein key to the genus Philopterus in the key of Mey (2004), based on having both trabecula and coni, an extensive hyaline margin, dorsal anterior plates that are longer than wide, and ventral carinae that are not recurved towards the preantennal nodi. However, other characters are quite variable among the species described here, and ascertaining homologous structures can be difficult, especially in the male genitalia. Moreover, one distinguishing character of Philopterus in Mey's key is the similarity in the length of the $o s$, pos, and $m t s 1-3$; yet, the relative lengths of these setae vary in the species treated here. The number and position of sensilla of the postantennal head also vary between 
species. Most likely, this variation corresponds to deep divisions between different groups of Philopterus sensu Mey (2004), some of which may ultimately be considered different genera or subgenera.

Many species of Philopterus are inadequately described, with much of the description being based on measurements, and most of the illustrations being of characters of limited taxonomic value (prosternal plates, shape of trabecula, single tergopleurites with only some of the setae illustrated). Finding suitable species to compare potential new species with is, therefore, often difficult. Here, we primarily compare our new species with other species from the same, or a closely related host family. In cases where known species of Philopterus on the same host family are clearly very different (e.g., Philopterus afropari sp. nov.), or where no species of Philopterus were described from the same host family, we expanded our comparison to species from other host families, principally ones in the same geographical region. In some cases (e.g., Philopterus hebes sp. nov.), no closely related species of Philopterus were identifiable.

We also referred to the species groups proposed by Złotorzycka \& Lucińska (1976); however, these species group are of limited use as they only include Central European species of Philopterus. Moreover, the morphological characters on which these species groups are based are sometimes hard to interpret, differ somewhat between species groups, and are of limited or unknown phylogenetic utility. Finally, all illustrations and descriptions in Złotorzycka's publications (e.g., Złotorzycka \& Lucińska 1976) are partial and poor, and not all species are illustrated. Nevertheless, the partial revisions of Philopterus in Złotorzycka \& Lucińska (1976) and Złotorzycka (1964) are the only published attempts to structure the species in Philopterus.

Philopterus hebes sp. nov. urn:Isid:zoobank.org:act:DACE58E4-5AB4-420A-A709-777B88A4824B

Figs 1-6; Tables 1-4

\section{Diagnosis}

It is difficult to ascertain which species of Philopterus is most similar to $P$. hebes sp. nov. The broad and relatively short preantennal head of $P$. hebes sp. nov. is reminiscent of that of $P$. chilchil Ansari, 1955 [ex Turdoides caudata caudata (Dumont, 1823); see Ansari (1958) for an illustration; type specimens of $P$. chilchil are presumed lost (Naz et al. 2020)]. Both $P$. hebes sp. nov. and P. chilchil have very broad dorsal anterior plates with broad posterior extensions. However, the illustrations of $P$. chilchil published by Ansari (1958) are inadequate to compare the two species properly; for instance, the subgenital plate and many head setae are absent in Ansari's illustration and not described in detail in the text. The male genitalia of $P$. chilchil are poorly illustrated and not described. From what can be seen in Ansari's illustrations, $P$. hebes sp. nov. can be separated from $P$. chilchil by the following characters: distal mesosome broadly triangular with pointed distal end in $P$. chilchil, but rounded with concave lateral margins in $P$. hebes sp. nov. (Figs 4-5); proximal mesosome extensive, with concave lateral margins and convex proximal margin in $P$. chilchil, but simple, with convergent convex lateral margins in $P$. hebes sp. nov. (Fig. 5); hyaline margin apparently very narrow and weakly concave in $P$. chilchil, but extensive, with moderate concavity in median section in P. hebes sp. nov. (Figs 1-3). Closer comparison of the genitalia of both sexes and chaetotaxy will have to await the redescription of $P$. chilchil.

A similar head shape is also found in Philopterus vittati Ansari, 1955 [ex Lanius vittatus Valenciennes, 1826; see Ansari (1956) for illustration; holotype presumed lost (Naz et al. 2020)]. These two species can be separated by the following characters: posterior extension of dorsal anterior plate narrow in $P$. vittati, but broad in $P$. hebes sp. nov. (Fig. 3); hyaline margin less extensive in P. vittati than in $P$. hebes sp. nov. (Fig. 3); female abdominal segments IV-V with 3 sts on each side in P. hebes sp. nov. (Fig. 2), but with 4 sts on each side in $P$. vittati ( $\mathrm{n}=3$ and 5 , respectively); female abdominal segment VI with 2 sts on each side in $P$. hebes sp. nov. (Fig. 2), but with 4 sts on each side in P. vittati; lateral accessory sternites present on abdominal segments II-VI and central sternal plate present on segment VI in 
P. vittati, but central sternal plates absent and lateral accessory sternal plates not visible (but may be poorly sclerotized) in $P$. hebes sp. nov. (Fig. 2). The male of $P$. vittati is unknown, and the species is in need of redescription before a more complete comparison can be made.

\section{Etymology}

The species name is derived from the Latin 'hebes' for 'blunt', referring to the shape of the preantennal area.

\section{Material examined}

\section{Holotype}

THAILAND - ${ }^{\text {; }}$; Chaiyaphum Province, Phukhieo, Ban Nan Khun; 11 Dec. 1952; R.E. Elbel leg.; ex Chloropsis aurifrons inornata; "RE-876-888, RT-B-17528"; NHMUK.

\section{Paratypes}

THAILAND • 1 ; ; same collection data as for holotype; NHMUK $-3 \hat{\jmath} \widehat{\jmath}, 3$ q $q$; Kamphaeng-Phet Province, Khanu, Salok Bat Ban Thung Chuak; 24 Jun. 1953; same collector and host as for holotype; “RE-2741, RT-B-21644”; PIPR.

\section{Other material}

THAILAND • 1 q; Loei Province, Tha Li Ban Muang Khai; 17 Jan. 1955; same collector as for holotype; ex Chloropsis cochinchinensis kinneari; "RE-4504, B-31119"; PIPR.

\section{Type host}

Chloropsis aurifrons inornata Kloss, 1918 - golden-fronted leafbird (Chloropseidae).

\section{Other host}

Chloropsis cochinchinensis kinneari Hall \& Deignan, 1956 - blue-winged leafbird.

\section{Description}

Head shape and chaetotaxy as in Fig. 3, preantennal area very broad. Hyaline margin wide, not extending much lateral to marginal carina, concave medianly. Dorsal anterior plate roughly pentagonal, anterior margin shallowly concave, lateral corners rounded. Ventral anterior plate wide, shallowly crescentshaped. Posterior margin of dorsal preantennal suture unclear in examined specimens. Coni slender, curved posteriorly. Gular plate small. Thoracic and abdominal segments as in Figs 1-2. Measurements as in Table 1.

\section{Male}

Thoracic and abdominal chaetotaxy as in Fig. 1 and Tables 2-4. Central sternal plates absent, lateral accessory plates present on segments II-VI. Basal apodeme slender, widening slightly anteriorly (Figs 4-5). Mesosome as in Figs 4-5, with 3 stout setae on each side. Parameres short, blunt (Figs 4-5), with pst 1-2 both apical.

\section{Female}

Thoracic and abdominal chaetotaxy as in Fig. 2 and Tables 2-4. Central sternal plates absent, lateral accessory plates not clearly visible. Subgenital plate and vulval margin as in Fig. 6; chaetotaxy as in Fig. 6 and Table 3. Subvulval plates with notch on lateral margin.

\section{Remarks}

Apart from size, no significant differences were found between specimens from the two host species. Philopterus hebes sp. nov. constitutes the first description of a species in the Philopterus complex, as well as the first ischnoceran louse, from hosts in the Chloropseidae. 


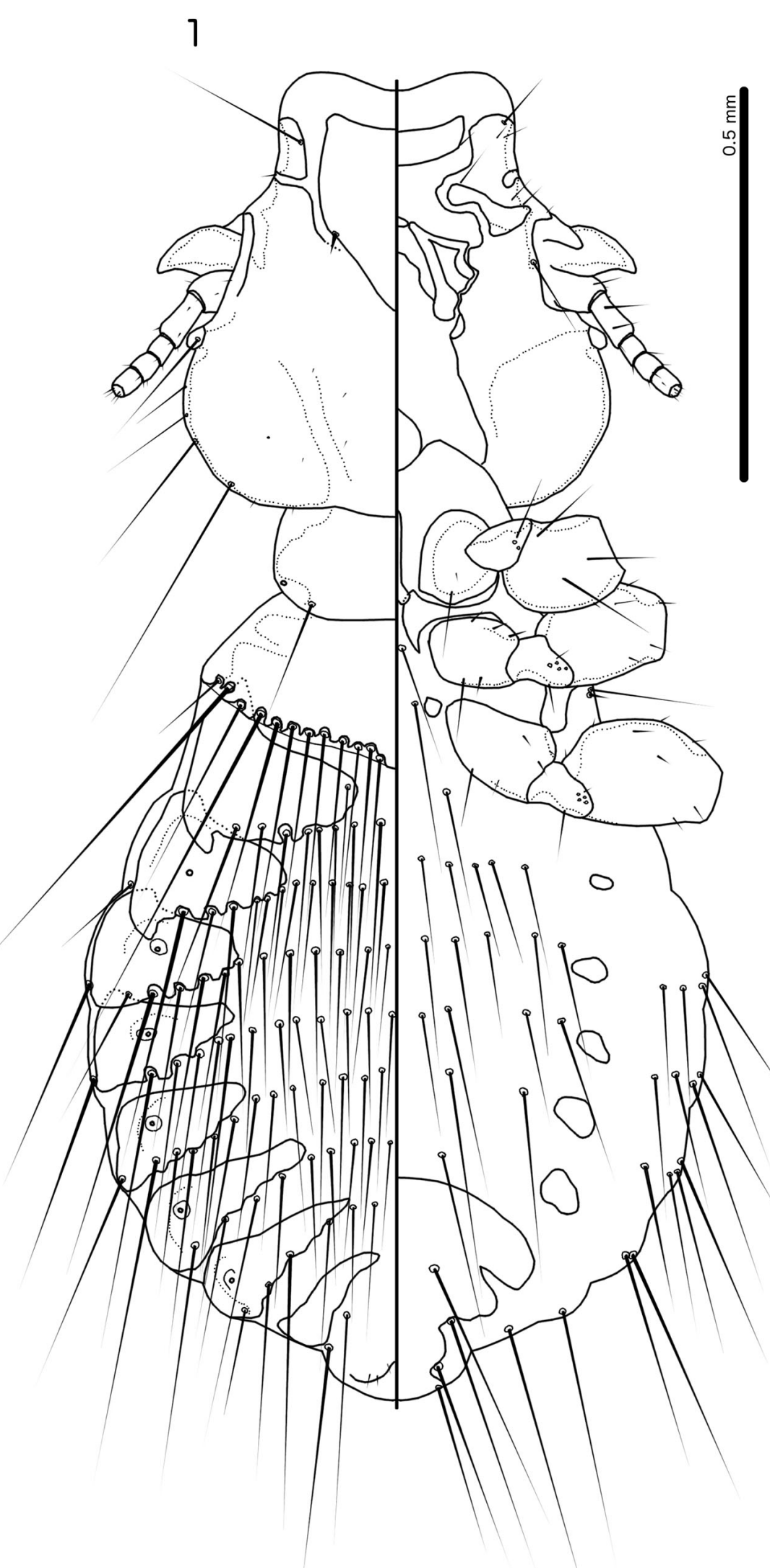

Fig. 1. Philopterus hebes sp. nov. ex Chloropsis aurifrons inornata Kloss, 1918, male habitus, dorsal and ventral views. 


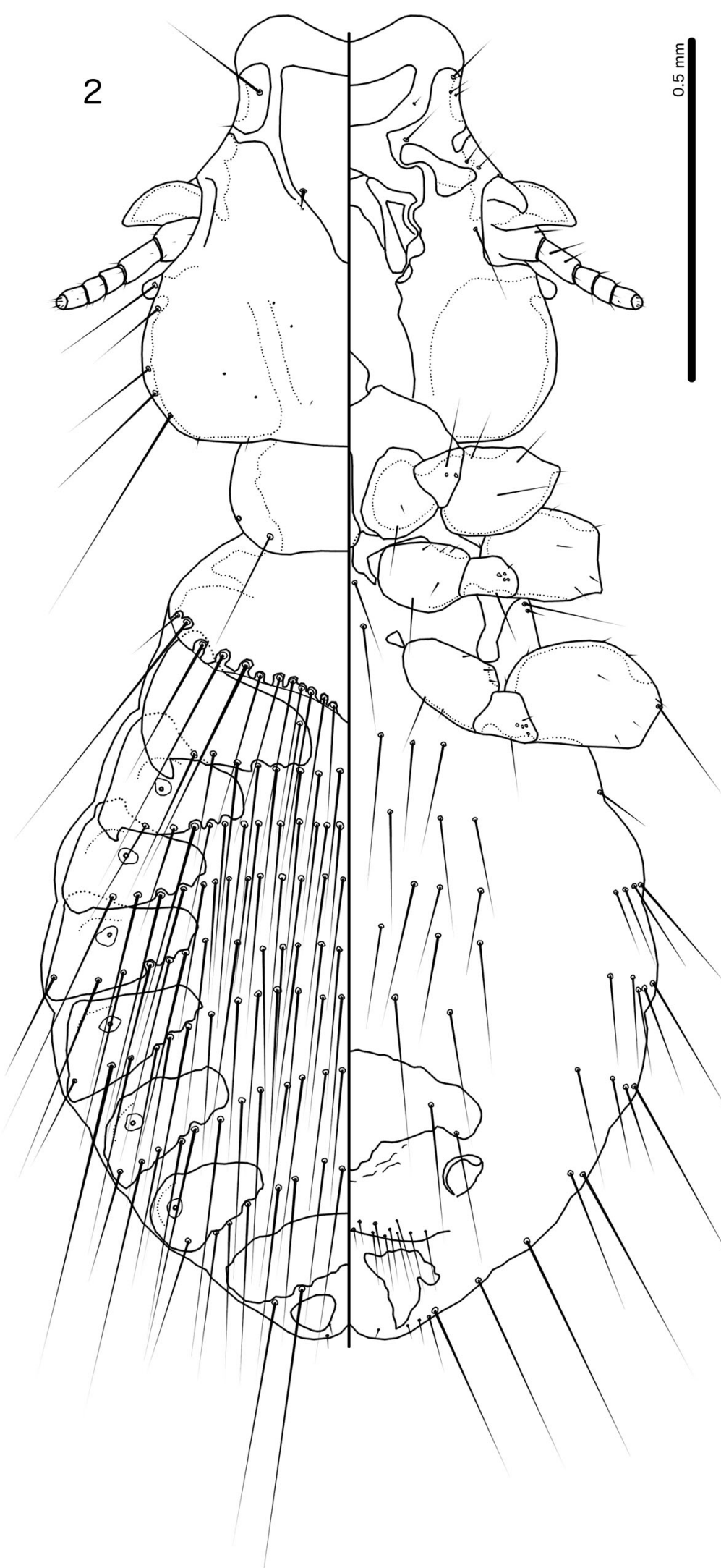

Fig. 2. Philopterus hebes sp. nov. ex Chloropsis aurifrons inornata Kloss, 1918, female habitus, dorsal and ventral views. 


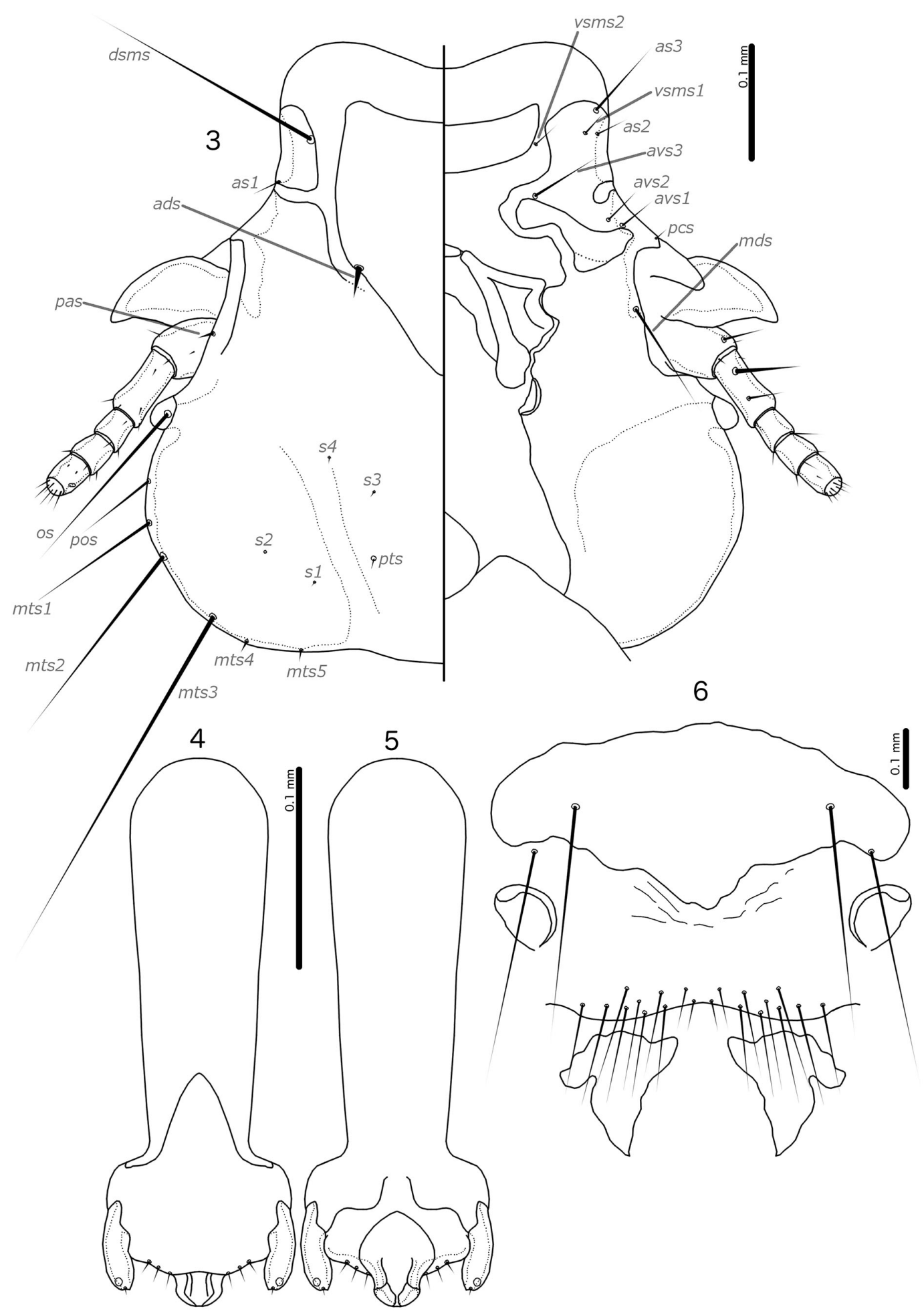

Figs 3-6. Philopterus hebes sp. nov. ex Chloropsis aurifrons inornata Kloss, 1918. 3. Male head, dorsal and ventral views. 4. Male genitalia, dorsal view. 5. Male genitalia, ventral view. 6. Female subgenital plate, vulval margin, and subvulval plates, ventral view. Abbreviations: $a d s=$ anterior dorsal seta; as $1-3=$ anterior setae $1-3 ;$ avs $1-3=$ anterior ventral setae $1-3$; dsms $=$ dorsal submarginal seta; $m d s=$ mandibular seta; $m t s 1-5=$ marginal temporal setae $1-5 ;$ os $=$ ocular seta; pas $=$ preantennal seta; $p c s=$ preconal seta; $p o s=$ preocular seta; $p t s=$ posttemporal seta; $s 1-4=$ sensilla $1-4 ;$ vsms $1-2=$ ventral submarginal setae $1-2$. 
Table 1. Measurements (in millimetres) of Philopterus hebes sp. nov. and P. micropunctatus sp. nov. Some dimensions (e.g., APLL, TPVL) are measured on both sides of the body, and intervals may therefore be given even if only one specimen was examined. Abbreviations: ADPL $=$ dorsal anterior plate length (at midline); $\mathrm{ADPW}=$ dorsal anterior plate width; $\mathrm{AL}=$ abdominal length (at midline); ANW $=$ anterior notch width; APLL $=$ dorsal anterior plate lateral length; AW $=$ abdominal width (at segment $\mathrm{V}$ ); $\mathrm{GL}=$ genital length (in male); $\mathrm{GW}=$ genital width (in male); $\mathrm{HL}=$ head length (at midline); $\mathrm{HW}=$ head width (at temples); $\mathrm{PAL}=$ preantennal length; $\mathrm{PAW}=$ preantennal width (at base of coni); $\mathrm{PMCL}=$ premarginal carina length; $\mathrm{POL}=$ postantennal length (at midline); $\mathrm{PRL}=$ prothoracic length; PRW = prothoracic width; PTL = pterothoracic length (at midline); PTW = pterothoracic width; SGPW = subgenital plate width (in female); $\mathrm{TL}=$ total length (at midline); $\mathrm{TPVL}=$ tergal plate $\mathrm{V}$ length; $\mathrm{TRL}=$ trabeculum length; TRW $=$ trabeculum width.

\begin{tabular}{|c|c|c|c|c|c|c|}
\hline & & \multicolumn{3}{|c|}{ Philopterus hebes sp. nov. } & \multirow{2}{*}{\multicolumn{2}{|c|}{$\begin{array}{c}\text { Philopterus micropunctatus sp. nov } \\
\text { Anthus hodgsoni } \\
\end{array}$}} \\
\hline & & \multicolumn{2}{|c|}{$\begin{array}{c}\text { Chloropsis aurifrons } \\
\text { inornata }\end{array}$} & \multirow{2}{*}{$\begin{array}{l}\begin{array}{c}\text { C. cochinchinensis } \\
\text { kinneari }\end{array} \\
(\mathrm{n}=1)^{3} \\
\end{array}$} & & \\
\hline & & $\widehat{\partial} \partial^{\lambda}(n=4)^{1}$ & $q+(\mathrm{n}=5)^{2}$ & & $\widehat{\partial}(\mathrm{n}=1)$ & 우우 $(\mathrm{n}=4)$ \\
\hline Total & TL & $1.55-1.68$ & $1.63-2.17$ & 2.10 & 1.38 & $1.56-1.74$ \\
\hline \multirow[t]{12}{*}{ Head } & HL & $0.52-0.55$ & $0.53-0.63$ & 0.60 & 0.50 & $0.51-0.53$ \\
\hline & HW & $0.52-0.54$ & $0.54-0.64$ & 0.61 & 0.47 & $0.48-0.51$ \\
\hline & ANW & $0.27-0.30$ & $0.28-0.33$ & 0.32 & 0.18 & $0.18-0.19$ \\
\hline & ADPL & $0.21-0.23$ & $0.23-0.29$ & 0.27 & 0.27 & $0.26-0.28$ \\
\hline & ADPW & $0.19-0.20$ & $0.19-0.33$ & 0.23 & 0.15 & 0.16 \\
\hline & APLL & $0.14-0.17$ & $0.15-0.19$ & $0.18-0.19$ & $0.17-0.18$ & $0.18-0.19$ \\
\hline & PMCL & 0.07 & $0.07-0.08$ & $0.08-0.09$ & 0.10 & $0.10-0.11$ \\
\hline & PAL & $0.12-0.14$ & $0.12-0.16$ & 0.15 & 0.16 & 0.18 \\
\hline & PAW & $0.28-0.36$ & $0.37-0.45$ & 0.43 & 0.31 & $0.31-0.33$ \\
\hline & POL & $0.28-0.30$ & $0.29-0.35$ & 0.33 & 0.25 & $0.25-0.27$ \\
\hline & TRL & $0.11-0.12$ & $0.11-0.13$ & $0.12-0.13$ & 0.10 & $0.09-0.11$ \\
\hline & TRW & $0.05-0.06$ & $0.05-0.07$ & $0.05-0.06$ & 0.04 & 0.04 \\
\hline \multirow[t]{4}{*}{ Thorax } & PRL & $0.13-0.14$ & $0.13-0.17$ & 0.14 & 0.11 & $0.11-0.15$ \\
\hline & PRW & $0.32-0.37$ & $0.33-0.38$ & 0.37 & 0.29 & $0.29-0.33$ \\
\hline & PTL & $0.19-0.21$ & $0.21-0.22$ & 0.24 & 0.16 & $0.16-0.17$ \\
\hline & PTW & $0.46-0.49$ & $0.48-0.58$ & 0.57 & 0.40 & $0.44-0.46$ \\
\hline \multirow[t]{3}{*}{ Abdomen } & $\mathbf{A L}$ & $0.66-0.81$ & $0.77-1.16$ & 1.13 & 0.63 & $0.75-0.95$ \\
\hline & AW & $0.73-0.84$ & $0.78-0.99$ & 0.98 & 0.56 & $0.61-0.73$ \\
\hline & TPVL & $0.13-0.14$ & $0.14-0.19$ & $0.18-0.19$ & $0.09-0.10$ & 0.12 \\
\hline \multirow[t]{3}{*}{ Genitals } & GL & $0.24-0.29$ & - & - & 0.20 & - \\
\hline & GW & 0.10 & - & - & 0.08 & - \\
\hline & SGPW & - & $0.42-0.49$ & - & - & 0.35 \\
\hline
\end{tabular}

${ }^{1}$ For PTW, $\mathrm{n}=3$ due to disruption of lateral margin of pterothorax in one specimen. For PTL, $\mathrm{n}=3$ as the posterior margin of the pterothorax is completely obscured by gut content in one specimen.

${ }^{2}$ For SGPW, $\mathrm{n}=4$ as subgenital plate is obscured by gut content in one specimen.

${ }^{3}$ Subgenital plate partially obscured by gut content and not measured. 
Table 2. Thoracic and abdominal chaetotaxy of the species of Philopterus Nitzsch, 1818 described in this paper. Only tergal seta are included here; for sternal setae, see Table 3; for pleural setae, see Table 4. Anterior margin of tergopleurite II has 1 seta on each side in all species, which is not listed in the table. Numbers denote the numbers of setae on one side of the abdomen only; for setal counts in the entire setal row of each segment, these numbers thus need to be doubled. Abbreviation: $m m s=$ marginal mesometathoracic setae.

\begin{tabular}{|c|c|c|c|c|c|c|c|c|c|c|}
\hline \multirow{2}{*}{ Louse } & \multirow{2}{*}{ Sex } & \multirow{2}{*}{$\frac{\text { Thoracic }}{m m s}$} & \multicolumn{8}{|c|}{ Tergal } \\
\hline & & & II & III & IV & $\mathbf{V}$ & VI & VII & VIII & $\mathbf{I X}+\mathbf{X}$ \\
\hline \multirow{2}{*}{$\begin{array}{l}\text { Philopterus afropari } \\
\text { sp. nov. }\end{array}$} & $\hat{\sigma}$ & $9-11$ & $6-8$ & $9-10$ & $10-12$ & $10-12^{3}$ & $10-12^{3}$ & $9-10$ & $4-6$ & 1 \\
\hline & q & 9 & $7-8$ & $10-12$ & $10-12$ & $10-12$ & $10-12$ & $9-10$ & 6 & 2 \\
\hline \multirow{2}{*}{$\begin{array}{l}\text { Philopterus coriaceus } \\
\text { sp. nov. }\end{array}$} & $\hat{0}$ & $11-12$ & 10 & $9-11$ & $9-11$ & $9-11$ & $9-11$ & $7-8$ & $3-5$ & 1 \\
\hline & q & $11-12$ & 10 & $10-12$ & $10-12$ & $10-12$ & 10 & $7-8,10^{1}$ & $4-6$ & $1-2^{2}$ \\
\hline \multirow{2}{*}{$\begin{array}{l}\text { Philopterus hebes } \\
\text { sp. nov. }\end{array}$} & $\hat{0}$ & $11-12$ & 8 & $11-12$ & $11-12$ & $11-12$ & $11-12$ & $7-9$ & $5-6$ & 2 \\
\hline & q & $11-12$ & $8-10$ & $12-13$ & $12-13$ & $12-13$ & $12-13$ & $12-13$ & 8 & 3 \\
\hline \multirow{2}{*}{$\begin{array}{l}\text { Philopterus micropunctatus } \\
\text { sp. nov. }\end{array}$} & $\sigma^{\pi}$ & $9-10$ & $7-8$ & $8-9$ & $8-9$ & $8-9$ & $8-9$ & $8-9$ & $5-6$ & 1 \\
\hline & q & $9-11$ & $8-10$ & $8-10$ & $8-10$ & $11-12$ & $9-11$ & 9 & $5-7$ & 1 \\
\hline \multirow{2}{*}{$\begin{array}{l}\text { Philopterus pseudhirundo } \\
\text { sp. nov. }\end{array}$} & $\hat{0}$ & 10 & 8 & $7-8$ & $9-10$ & $9-10$ & 8 & 7 & $4-5$ & 1 \\
\hline & q & 9 & 6 & $7-9$ & $9-10$ & $10-11$ & $7-8$ & 5 & $4-5$ & 1 \\
\hline \multirow{2}{*}{$\begin{array}{l}\text { Philopterus sinensis } \\
\text { sp. nov. }\end{array}$} & $\hat{\sigma}$ & $8-9$ & 7 & $8-9$ & $6-7^{4}$ & 8 & $6-8^{4}$ & $6-7$ & $4-5$ & 1 \\
\hline & q & $9-10$ & 6 & $7-8$ & $7-8$ & $9-10$ & $7-8$ & $7-8$ & 5 & 1 \\
\hline \multirow{2}{*}{$\begin{array}{l}\text { Philopterus stansburyensis } \\
\text { sp. nov. }\end{array}$} & $\sigma^{\lambda}$ & $11-13$ & $10-11$ & $10-11$ & $10-11$ & $10-11$ & $8-12$ & $8-10$ & 5 & 1 \\
\hline & q & $14-15$ & $10-11$ & $11-13$ & $12-14$ & $11-13$ & $10-12$ & $10-11$ & $5-7$ & 1 \\
\hline \multirow{2}{*}{$\begin{array}{l}\text { Philopterus trepostephanus } \\
\text { sp. nov. }\end{array}$} & $\hat{0}$ & $9-11$ & $7-8$ & $7-9$ & $9-10$ & $9-10$ & $9-10$ & $7-9$ & $4-5$ & 1 \\
\hline & q & $10-11$ & $7-8$ & 9 & $10-11$ & $10-11$ & $9-10$ & $7-8$ & $4-5$ & 2 \\
\hline
\end{tabular}

${ }^{1} 7-8$ in one examined female, 10 in the other.

${ }^{2}$ In addition, there is 1 seta on each side at the anterior end of this segment.

${ }^{3}$ One male with 8 setae on one side of these segments.

${ }^{4}$ Setal rows of these segments have significant gaps, indicating that $1-2$ setae may be absent in the single examined male, but present if more males were examined. These numbers are thus preliminary.

Philopterus micropunctatus sp. nov. urn:1sid:zoobank.org:act:2A337930-2324-465E-95D6-8F7EC902C9ED

Figs 7-12; Tables 1-4

\section{Diagnosis}

Several species of Philopterus have been described from motacillid hosts; however, few of them are adequately described or illustrated. Złotorzycka \& Lucińska (1976) erected the P. passerinus species group based on size, the shape of the trabecula, the shape and chaetotaxy of the male subgenital plate, and the size of the male parameres. They placed Philopterus passerinus (Denny, 1842) (ex Motacilla alba Linnaeus, 1758), P. pavidus (Złotorzycka, 1964) (ex Motacilla flava Linnaeus, 1758), P. vultuosus Złotorzycka, 1964 (ex Anthus trivialis trivialis (Linnaeus, 1758)), and P. hanzaki Balát, 1955 (ex Anthus spinoletta spinoletta (Linnaeus, 1758)) in this group. The other two known species from motacillid hosts, P. irkutensis Fedorenko, 1985 (ex Anthus richardi Vieillot, 1818) and P. subitus Fedorenko, 1985 (ex Motacilla cinerea Tunstall, 1771) may also be closely related to the P. passerinus group, based on the shape of the parameres and trabecula in the original descriptions. However, a complete revision of the Philopterus species on motacillid hosts is sorely needed. 
Table 3. Abdominal and vulval chaetotaxy of the species of Philopterus Nitzsch, 1818 described in this paper. Only sternal setae are listed here; for tergal setae, see Table 2; for pleural setae, see Table 4. Numbers denote the numbers of setae on one side of the abdomen only; for setal counts in the entire setal row of each segment, these numbers thus need to be doubled.

\begin{tabular}{|c|c|c|c|c|c|c|c|c|c|c|c|c|}
\hline \multirow{2}{*}{ Louse } & \multirow{2}{*}{ Sex } & \multicolumn{8}{|c|}{ Sternal } & \multicolumn{3}{|c|}{ Vulval } \\
\hline & & II & III & IV & V & VI & VII & VIII & $\mathbf{I X}+\mathbf{X}$ & Long & Medium & Short \\
\hline \multirow{2}{*}{$\begin{array}{l}\text { Philopterus afropari } \\
\text { sp. nov. }\end{array}$} & $\sigma^{\lambda}$ & $3-4$ & $3-4$ & $4-5$ & $4-5$ & $4-5$ & 1 & 1 & 1 & - & - & - \\
\hline & q & $3-4$ & $4-5$ & $4-5$ & $4-5$ & $4-5$ & 2 & 0 & 0 & $3-7$ & 0 & $0-2$ \\
\hline \multirow{2}{*}{$\begin{array}{l}\text { Philopterus coriaceus } \\
\text { sp. nov. }\end{array}$} & 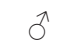 & $5-6$ & $5-6$ & $5-6$ & $4-5$ & $4-5$ & 1 & 1 & 1 & - & - & - \\
\hline & q & 6 & $6-7$ & $5-6$ & $4-5$ & 4 & 2 & 0 & 0 & $8-10$ & $0-1$ & $2-4$ \\
\hline \multirow{2}{*}{$\begin{array}{l}\text { Philopterus hebes } \\
\text { sp. nov. }\end{array}$} & $\hat{\sigma}$ & $3-5$ & $3-5$ & $3-5$ & 2 & 1 & 1 & 1 & 1 & - & - & - \\
\hline & $q$ & $2-3$ & $2-3$ & $2-3$ & $2-3$ & $2-3$ & $2-3$ & 0 & 0 & $7-8$ & 0 & $2-3$ \\
\hline \multirow{2}{*}{$\begin{array}{l}\text { Philopterus micropunctatus } \\
\text { sp. nov. }\end{array}$} & $\widehat{0}$ & $4-5$ & 6 & 6 & 5 & 5 & 1 & 1 & 1 & - & - & - \\
\hline & q & $3-5$ & $4-6$ & $4-6$ & $4-6$ & $4-6$ & 2 & 0 & 0 & 3 & $2-3$ & $1-3$ \\
\hline \multirow{2}{*}{$\begin{array}{l}\text { Philopterus pseudhirundo } \\
\text { sp. nov. }\end{array}$} & $\hat{\sigma}$ & $4-5$ & $7-8$ & $5-6$ & $5-6$ & 4 & 1 & 1 & 1 & - & - & - \\
\hline & q & 5 & $5-7$ & $6-7$ & $6-7$ & $6-7$ & 2 & 0 & 0 & 5 & 0 & $3-4$ \\
\hline \multirow{2}{*}{$\begin{array}{l}\text { Philopterus sinensis } \\
\text { sp. nov. }\end{array}$} & $\hat{\sigma}$ & $3-4$ & 6 & $4-5$ & $4-5$ & $4-5$ & 1 & 1 & 1 & - & - & - \\
\hline & q & 4 & 6 & 6 & 5 & 5 & 2 & 0 & 0 & 4 & 0 & $3-4$ \\
\hline \multirow{2}{*}{$\begin{array}{l}\text { Philopterus stansburyensis } \\
\text { sp. nov. }\end{array}$} & $\delta^{2}$ & $3-4$ & $3-4$ & $3-4$ & 2 & $2-3$ & 1 & 1 & 1 & - & - & - \\
\hline & $q^{3}$ & $4-5$ & $3-5$ & $4-5$ & $3-4$ & $3-5$ & 2 & 0 & 0 & $6-8$ & $0-1^{4}$ & 1 \\
\hline \multirow{2}{*}{$\begin{array}{l}\text { Philopterus trepostephanus } \\
\text { sp. nov. }\end{array}$} & $\hat{\sigma}$ & $4-5$ & $4-5^{1}$ & $4-5$ & $4-5$ & $4-5$ & 1 & 1 & $2-3$ & - & - & - \\
\hline & q & 3 & $5-6$ & $5-6$ & $4-5$ & $4-5$ & 2 & 0 & 0 & $5-6$ & 0 & $3-4$ \\
\hline
\end{tabular}

${ }^{1}$ One specimen with 7 sternal setae on one side. Segments V-VI with additional, shorter sternal setae lateral to those associated with the sternal plate.

${ }^{2}$ Two examined specimens with many sternal setae seemingly absent, and more material is necessary to confirm chaetotaxy of this species.

${ }^{3}$ Two of three examined specimens with many sternal setae absent; the numbers mostly derived from single specimen.

${ }^{4}$ All examined specimens with 1 medium seta on the left side and none on the right side.

The most distinctive character of $P$. micropunctatus sp. nov. is the elongated preantennal head and very long dorsal anterior plate (Fig. 9). The fragmented 'dots' between the female subvulval plates in P. micropunctatus sp. nov. (Fig. 12) are not found in any other species in the P. passerinus group we have examined. The shape of the head and dorsal anterior plate separates P. micropunctatus sp. nov. from P. irkutensis, P. subitus, P. passerinus, and P. vultuosus. Balát's (1955) only illustration of $P$. hanzaki is of the dorsal anterior plate, which is shorter than that of $P$. micropunctatus sp. nov. and with a differently shaped posterior projection. No illustration of P. pavidus has ever been published, and Eichler's text description (in Eichler 1953, as Docophorus passerinus Denny, 1842; Złotorzycka's replacement name $P$. pavidus was based on this description) does not contain enough detail to separate $P$. pavidus from any other Philopterus, regardless of host.

\section{Etymology}

The species name is derived from the Greek 'mikro' for 'small' and the Latin 'punctatus' for 'dotted', referring to the many small dots median to the subvulval plates. 
Table 4. Abdominal chaetotaxy of the species of Philopterus Nitzsch, 1818 described in this paper. Only pleural setae are listed here; for tergal setae, see Table 2; for sternal setae, see Table 3. Numbers denote the numbers of setae on one side of the abdomen only; for setal counts in the entire setal row of each segment, these numbers thus need to be doubled. Abbreviations: ant. $=$ anterior end; post. $=$ posterior end.

\begin{tabular}{|c|c|c|c|c|c|c|c|c|c|c|}
\hline \multirow{2}{*}{ Louse } & \multirow{2}{*}{ Sex } & \multicolumn{9}{|c|}{ Pleural } \\
\hline & & II & III & IV & $\mathbf{V}$ & VI & VII & VIII & IX+X (ant.) & $\overline{I X+X \text { (post.) }}$ \\
\hline \multirow{2}{*}{$\begin{array}{l}\text { Philopterus afropari } \\
\text { sp. nov. }\end{array}$} & $\hat{0}$ & 0 & 1 & $3-4$ & $3-4$ & $4-5$ & $3-4$ & 2 & 1 & 0 \\
\hline & q & 0 & 1 & 4 & 4 & 4 & 3 & 2 & 1 & 3 \\
\hline \multirow{2}{*}{$\begin{array}{l}\text { Philopterus coriaceus } \\
\text { sp. nov. }\end{array}$} & $\hat{0}$ & 0 & 1 & $4-5$ & $4-5$ & $3-4$ & $2-3$ & 2 & 1 & 0 \\
\hline & 우 & 0 & 1 & 4 & 4 & 4 & $2-3$ & 2 & 1 & 3 \\
\hline \multirow{2}{*}{$\begin{array}{l}\text { Philopterus hebes } \\
\text { sp. nov. }\end{array}$} & 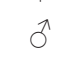 & 0 & 1 & $5-6$ & $5-6$ & $5-6$ & 3 & 2 & 1 & 0 \\
\hline & o & 0 & 1 & $4-5$ & $4-5$ & $4-5$ & 3 & 2 & 1 & $3-4$ \\
\hline \multirow{2}{*}{$\begin{array}{l}\text { Philopterus micropunctatus } \\
\text { sp. nov. }\end{array}$} & $\hat{0}$ & 0 & 1 & 3 & $3-4$ & 4 & 3 & 2 & 1 & 0 \\
\hline & q & 0 & 1 & $4-5$ & $4-5$ & $4-5$ & $2-3$ & 2 & 1 & 2 \\
\hline \multirow{2}{*}{$\begin{array}{l}\text { Philopterus pseudhirundo }{ }^{1} \\
\text { sp. nov. }\end{array}$} & 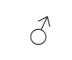 & 0 & 1 & $4-5$ & 5 & 5 & 4 & 2 & 1 & 0 \\
\hline & o & 0 & 1 & $5-7$ & $5-7$ & $5-7$ & 3 & 3 & 1 & 3 \\
\hline \multirow{2}{*}{$\begin{array}{l}\text { Philopterus sinensis } \\
\text { sp. nov. }\end{array}$} & $\widehat{\sigma}$ & 0 & 0 & $2-3$ & $2-3$ & 4 & 4 & 3 & 0 & 0 \\
\hline & q & 0 & 0 & 3 & 3 & 4 & 4 & 3 & 1 & 3 \\
\hline \multirow{2}{*}{$\begin{array}{l}\text { Philopterus stansburyensis } \\
\text { sp. nov. }\end{array}$} & $\hat{\sigma}$ & 0 & 1 & $3-4$ & $2-4$ & $2-6$ & $1-3$ & $2-3$ & 1 & 0 \\
\hline & o & 0 & 1 & $4-5$ & $5-8$ & $5-6$ & $3-5$ & $2-3$ & 1 & 3 \\
\hline \multirow{2}{*}{$\begin{array}{l}\text { Philopterus trepostephanus } \\
\text { sp. nov. }\end{array}$} & 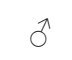 & 0 & 0 & 4 & 4 & 5 & 4 & 3 & 1 & 0 \\
\hline & o & 0 & 0 & 4 & 4 & 5 & 4 & 4 & 1 & 3 \\
\hline
\end{tabular}

${ }^{1}$ Segments V-VI with additional, shorter sternal setae lateral to those associated with the sternal plate; on segment IV of single examined male these are closer to the pleural setae, and these setae are therefore here included in the count of pleural setae on all segments.

\section{Material examined}

\section{Holotype}

THAILAND • ô; Nan Province, Bun Yun, Pang Nam Un; 21 Jan. 1953; R.E. Elbel and H.G. Deignan leg.; ex Anthus hodgsoni; "RE-2103, RT-B-17720"; NHMUK.

\section{Paratypes}

THAILAND • 1 ; ; same collection data as for holotype; NHMUK $\bullet 3 q+q$; same collection data as for holotype; PIPR.

\section{Type host}

Anthus hodgsoni Richmond, 1907 - olive-backed pipit (Motacillidae).

\section{Description}

Head shape and chaetotaxy as in Fig. 9, preantennal area moderately broad. Hyaline margin wide, slightly concave medianly, not extending much lateral to marginal carina. Dorsal preantennal plate long, narrowing gently posteriorly, with distinct lateral thickenings along much of lateral margins anterior to ads. Ventral anterior plate bluntly crescent-shaped. Coni small, pointed posteriorly. Thoracic and abdominal segments as in Figs 7-8. Measurements as in Table 1. 


\section{Male}

Thoracic and abdominal chaetotaxy as in Fig. 7 and Tables 2-4. Central sternal plates absent on segments II-VI. Lateral accessory plates present on segments III-VI. Subgenital plate broad, but diffuse distally and illustrated approximately. Basal apodeme short and slender (Figs 10-11). Mesosomal thickening

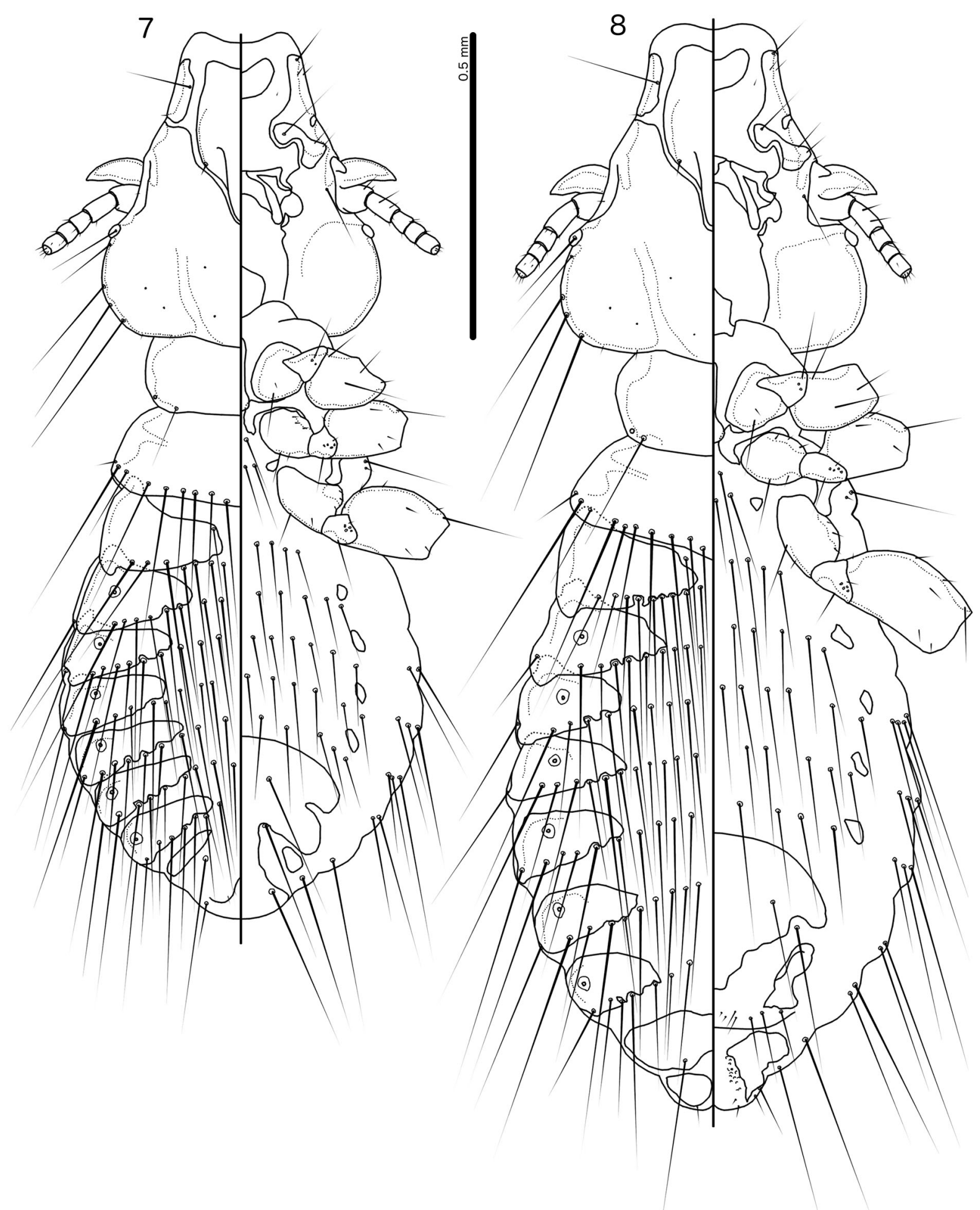

Figs 7-8. Philopterus micropunctatus sp. nov. ex Anthus hodgsoni Richmond, 1907. 7. Male habitus, dorsal and ventral views. 8. Female habitus, dorsal and ventral views. 


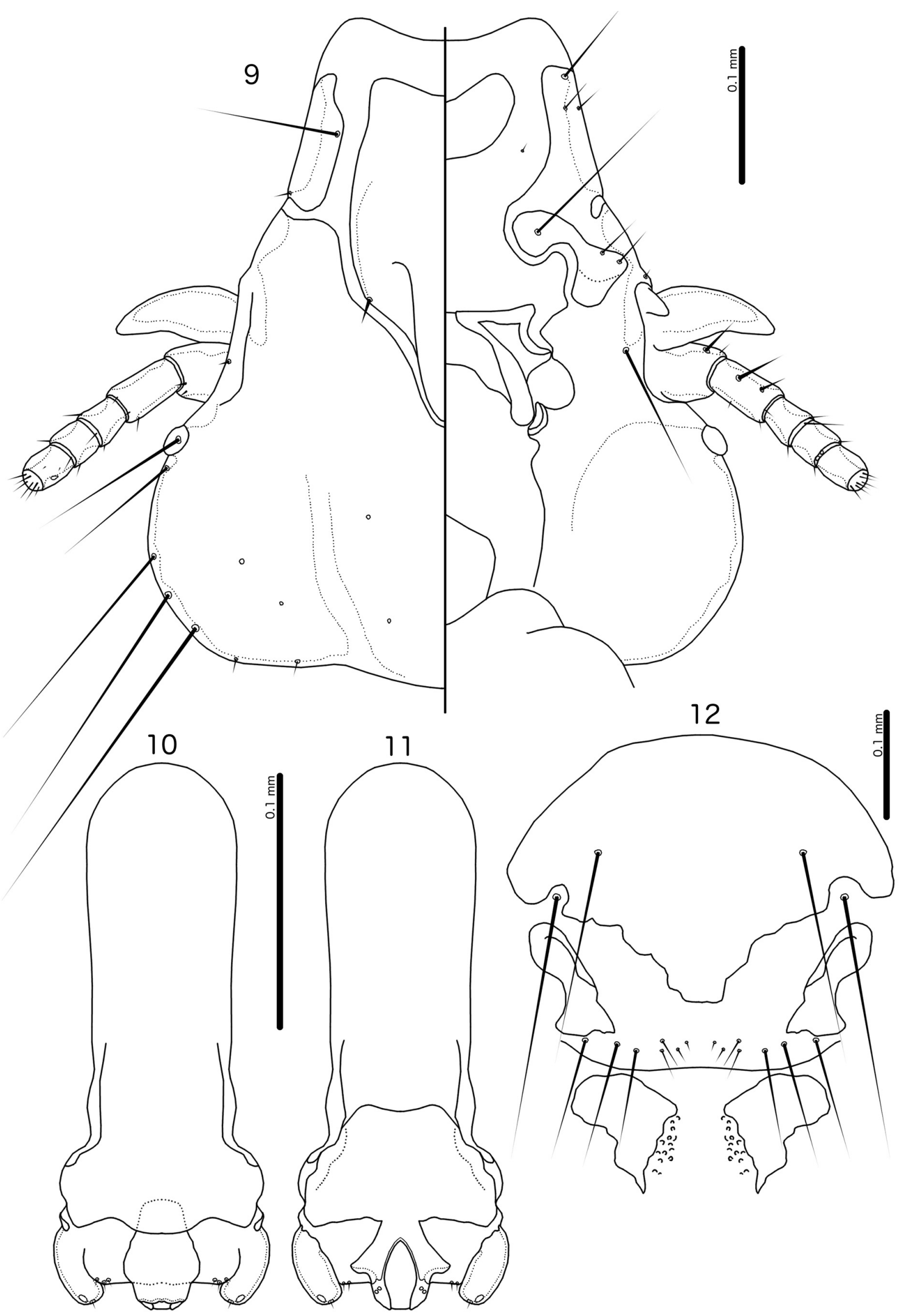

Figs 9-12. Philopterus micropunctatus sp. nov. ex Anthus hodgsoni Richmond, 1907. 9. Male head, dorsal and ventral views. 10. Male genitalia, dorsal view. 11. Male genitalia, ventral view. 12. Female subgenital plate, vulval margin, and subvulval plates, ventral view. 
truncated oval; mesosome with 3 microsetae on each side (Fig. 10). Gonopore bluntly lanceolate, with wide, roughly triangular sclerotization anterior and lateral to opening, proximally fused to basal apodeme; 2 sensilla on each side of gonopore. Parameres short and stocky (Figs 10-11); pst1-2 as in Fig. 10.

\title{
Female
}

Thoracic and abdominal chaetotaxy as in Fig. 8 and Tables 2-4. Central sternal plates absent on segments II-VI. Lateral accessory plates present on segments III-VI. Subgenital plate as in Fig. 12; lateral sclerotizations of vulval area extended posteriorly to approach vulval margin; in one female also extended anteriorly to fuse with subgenital plate. Vulval margin more or less straight, chaetotaxy as in Fig. 12 and Table 3. Subvulval plates slender distally, with many small fragmentary dots between plates as in Fig. 12.

\author{
Philopterus afropari sp. nov. \\ urn:1sid:zoobank.org:act:6737F5C9-8DE2-4074-9C6E-BD62F2E4E10D
}

Figs 13-18; Tables 2-5

\section{Diagnosis}

Philopterus afropari sp. nov. is not similar to any species of Philopterus known from Holarctic parid hosts, which are all characterized by having the dorsal anterior plate with pointed postero-lateral corners near ads on each side, 3-4 setae on each side on the posterior margin of the pronotum, and a long and narrow basal apodeme (Fedorenko \& Vasjukova 1985; Mey 1988, 1994). In contrast, P. afropari sp. nov. lacks the pointed corners of the dorsal anterior plate, has only one posterior seta on each side of the pronotum, and has a broader basal apodeme. No species of Philopterus has been described from other African parids.

Philopterus afropari sp. nov. is somewhat similar to P. solus Tendeiro, 1962, another African species associated with a host in the Bucerotiformes (Rhinopomastus cyanomelas schalowi Neumann, 1900). These two species share the following characters: hyaline margin wide but relatively short; dorsal anterior plate broadly trapezoidal; coni small with concave anterior margins; male subgenital plate with at least 2 lateral lobes on each side and a lateral accessory sternal plate on abdominal segment IX+X (fused with subgenital plate in one specimen examined in Tendeiro 1962). Most notably, the gonopore of both species is of similar shape and the ventral section of the mesosome is largely indistinguishable from the distal basal apodeme in both species; dorsally, the mesosome of $P$. afropari sp. nov. (Fig. 16) appears to be similar to the dark section of the distal basal apodeme in Tendeiro's photo of $P$. solus, but this section is not clearly illustrated by Tendeiro (1962), and the photo is of poor quality.

These two species can be separated by the following characters: os and pos of more or less equal length in P. afropari sp. nov. (Fig. 15), but pos much longer than os in P. solus; preantennal head longer and more slender in P. afropari sp. nov. (Fig. 15) than in P. solus; central sternal plates evidently absent in males of $P$. solus, but present in males of $P$. afropari sp. nov. (Fig. 13); lateral lobes of male subgenital plate of roughly equal size in $P$. solus, but posterior lobe much larger than anterior lobe in $P$. afropari sp. nov. (Fig. 13); basal apodeme in $P$. solus with clear central thickenings presumably associated with the endophallus, but no such structures visible in P. afropari sp. nov. (Figs 16-17); central posterior extension of the female subgenital plate more prominent in P. afropari sp. nov. (Fig. 18) than in P. solus. Note that $P$. solus is in need of a more detailed redescription before a complete comparison between these two species can be made.

\section{Etymology}

The specific name refers to the fact that this is the first species of the Philopterus complex described from African parids. 
Material examined

\section{Holotype}

SOUTH AFRICA • Õ; Transvaal, Potchefstroom; 27 Jul. 1952; [F.] Zumpt leg.; ex Melaniparus cinerascens cinerascens (as Parus cinerascens); "I.N. 1373/29"; MFN.

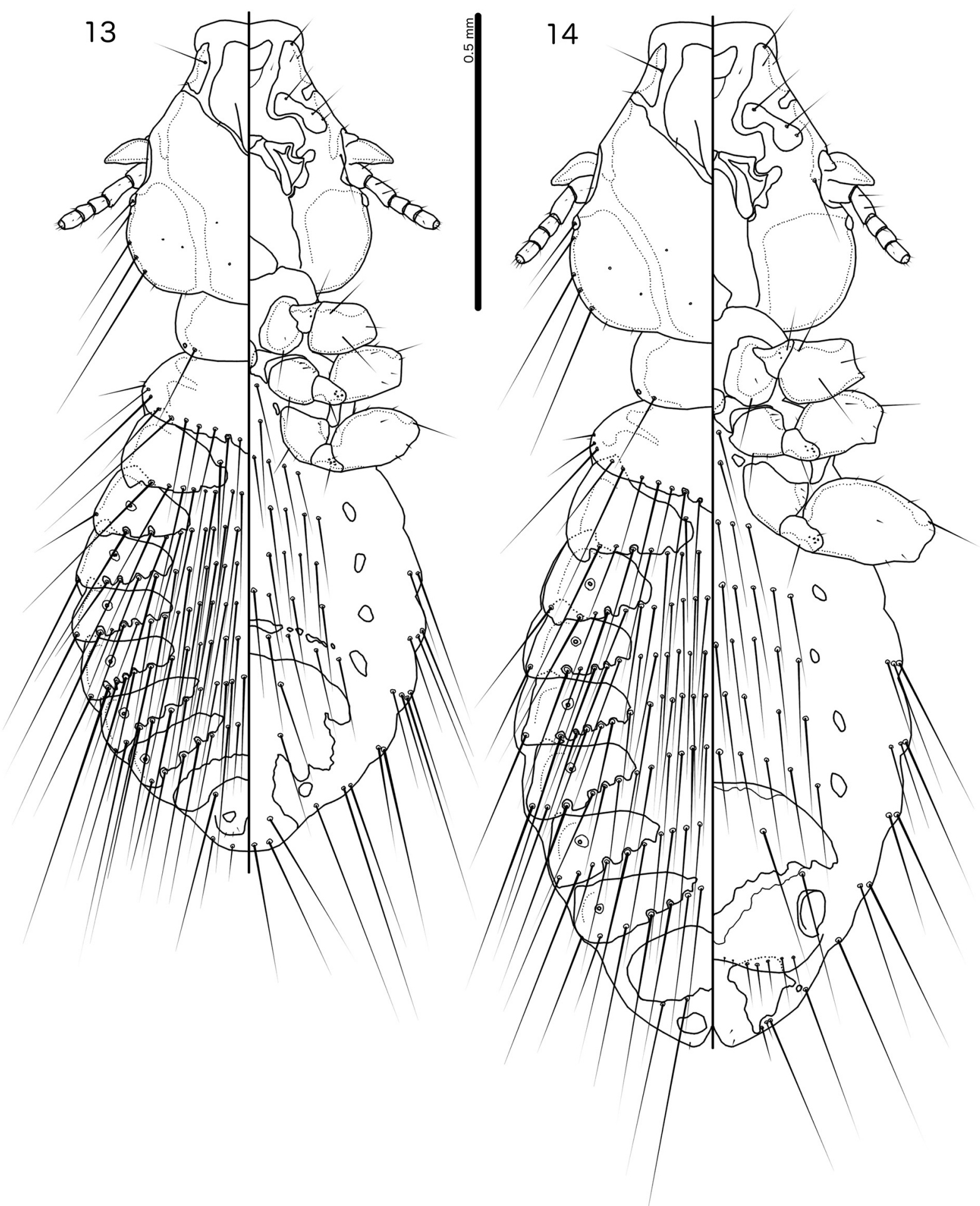

Figs 13-14. Philopterus afropari sp. nov. ex Melaniparus cinerascens cinerascens (Vieillot, 1818). 13. Male habitus, dorsal and ventral views. 14. Female habitus, dorsal and ventral views. 


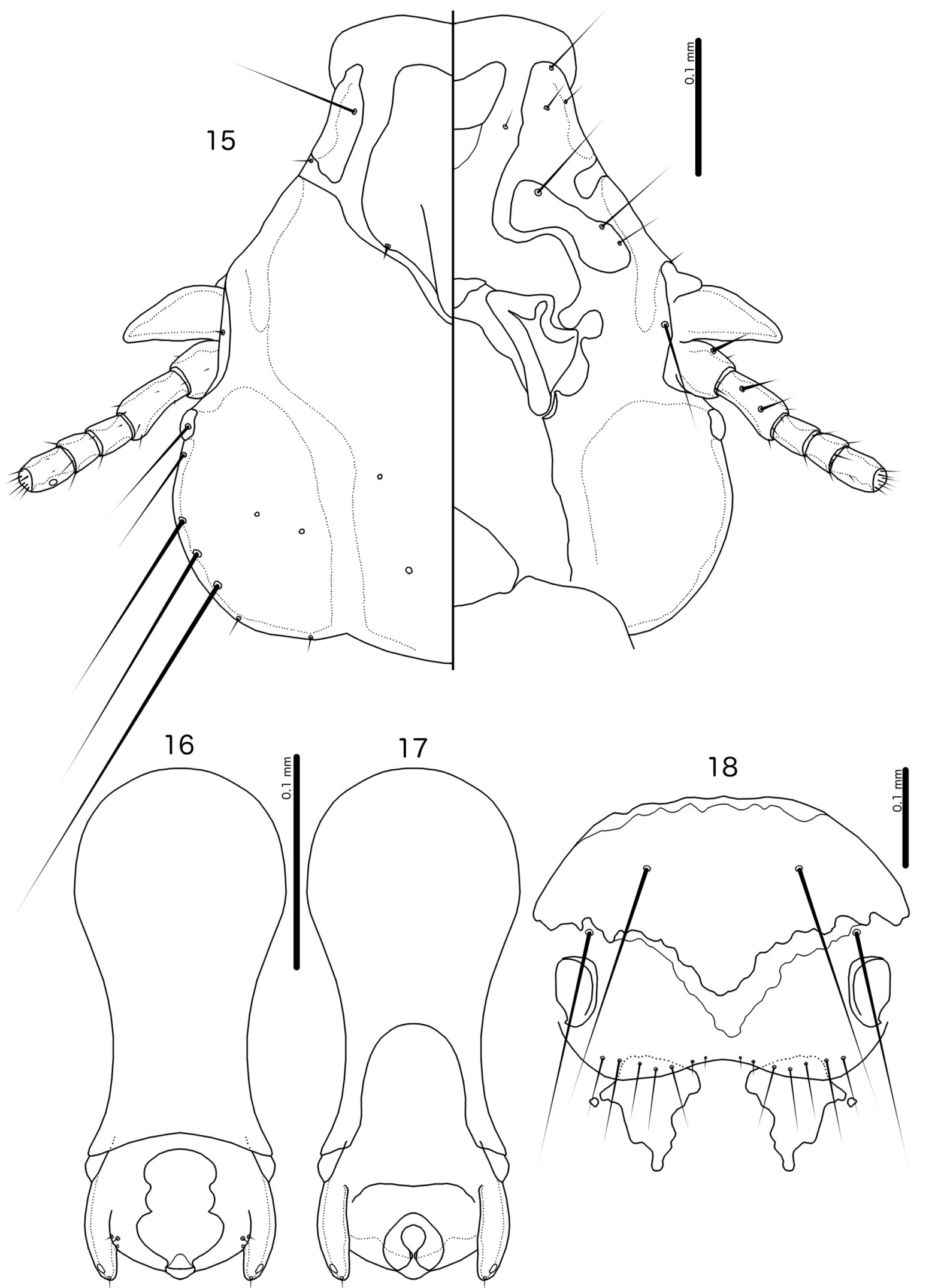

Figs 15-18. Philopterus afropari sp. nov. ex Melaniparus cinerascens cinerascens (Vieillot, 1818). 15. Male head, dorsal and ventral views. 16. Male genitalia, dorsal view. 17. Male genitalia, ventral view. 18. Female subgenital plate, vulval margin, and subvulval plates, ventral view. 


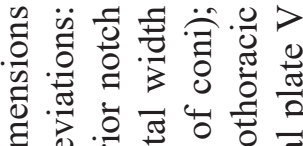

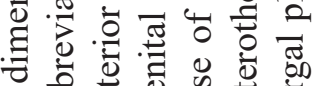

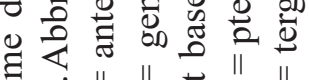

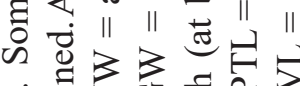

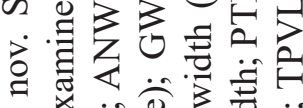

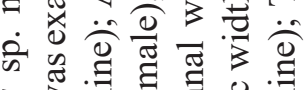

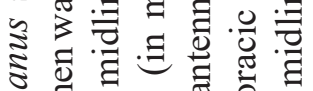

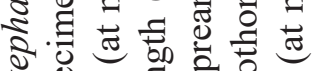
क्षे

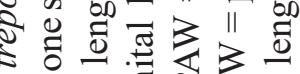

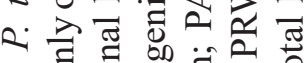
च

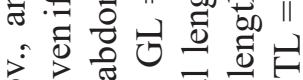
这 它.

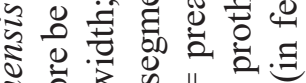
今.

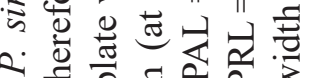
Q

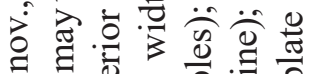

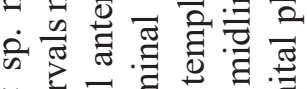

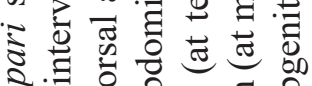

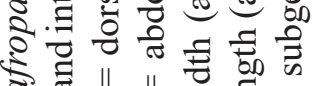

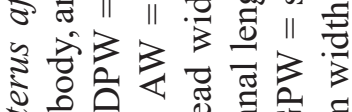

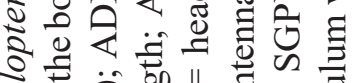

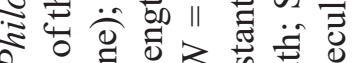

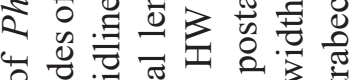

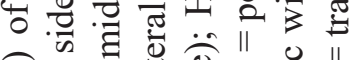

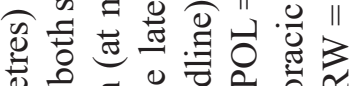
要

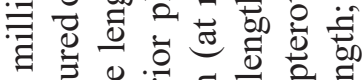

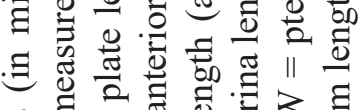

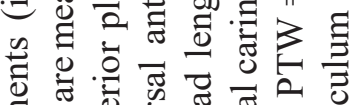

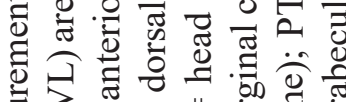

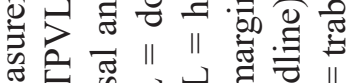

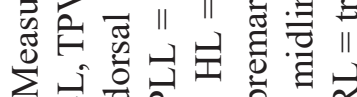
$\sum_{10}$

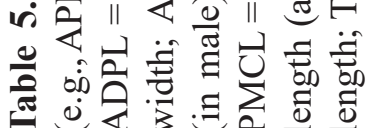

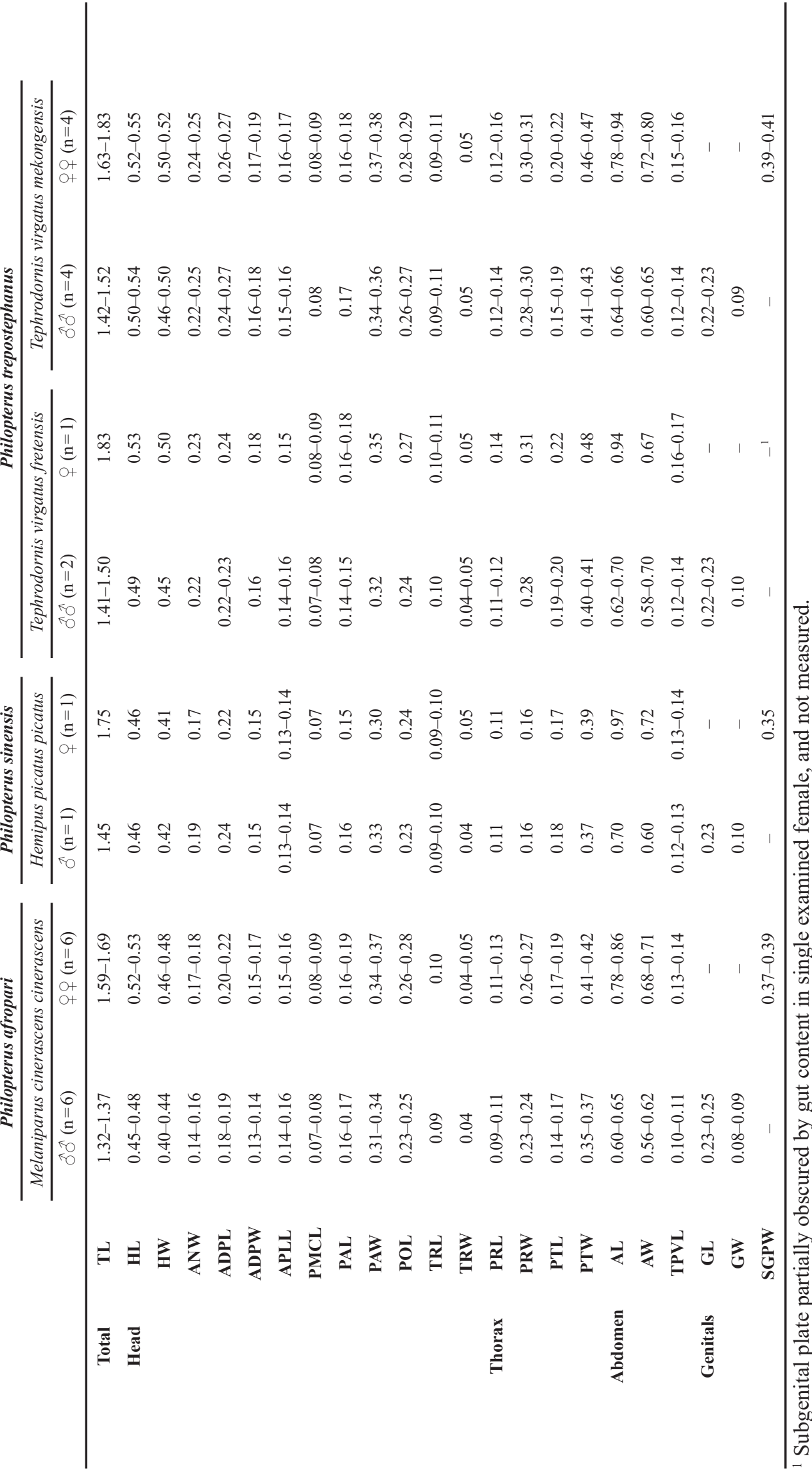


Paratypes

SOUTH AFRICA $・ 1 \hat{\jmath}, 4 \uparrow q$; same collection data as for holotype; MFN $\bullet 4 \hat{\jmath} \widehat{\partial}, 2 q q$; same collection data as for holotype but 24 Apr. 1952; "I.N. 1373/28"; MFN.

\section{Type host}

Melaniparus cinerascens cinerascens (Vieillot, 1818) - ashy tit (Paridae).

\section{Description}

Head shape and chaetotaxy as in Fig. 15, preantennal area broad. Hyaline margin wide, extending laterally beyond marginal carina, shallowly concave medianly. Dorsal anterior plate broad, trapezoidal, with broad, blunt posterior extension. Ventral anterior plate roughly triangular, with shallowly concave anterior margin. Coni small, distal end in some specimens curved slightly anteriorly. Gular plate small, irregular. Thoracic and abdominal segments as in Figs 13-14. Measurements as in Table 5.

\section{Male}

Thoracic and abdominal chaetotaxy as in Fig. 13 and Tables 2-4. Tergopleurite IX+X medianly continuous. Abdominal segments II-V with no central sternal plate, but with lateral accessory plates; segment VI with narrow, typically very fragmented central sternal plate and large lateral accessory plates. Subgenital plate with 3 lateral lobes on each side and small lateral accessory plate of segment $\mathrm{IX}+\mathrm{X}$. Basal apodeme broad (Figs 16-17), much constricted at mid-length. Mesosomal thickening large, with sinuous lateral margins and distal thickening (Fig. 16); 3 microsetae on each side of mesosome. Gonopore large (Fig. 17), widening distally. Parameres fused to basal apodeme, slender; pst1-2 as in Fig. 17.

\section{Female}

Thoracic and abdominal chaetotaxy as in Fig. 14 and Tables 2-4. Subgenital plate as in Fig. 18, with more weakly sclerotized sections on anterior and posterior ends. Vulval margin concave medianly (Fig. 18), chaetotaxy as in Fig. 18 and Table 3. Subvulval plate large, irregularly triangular, often with minute accessory plate laterally.

\section{Philopterus sinensis sp. nov. urn:lsid:zoobank.org:act:B2FE927B-B909-4E22-B95C-4A510355A188}

Figs 19-24; Tables 2-5

\section{Diagnosis}

Philopterus sinensis sp. nov. does not appear to be morphologically close to any other known species of the genus, but is somewhat similar to P. trepostephanus sp. nov., with which it shares the following characters: $m t s 1$ relatively short in male (Figs 19, 25), but longer in female (Figs 20, 26); gonopore with postero-lateral bulges, each of which is associated with 2 microsetae (Figs 23, 29); female genital setae displaced anteriorly from vulval margin (Figs 24, 30), particularly the more median setae; abdominal segment III without $p s$ in both sexes (Figs 19-20, 25-26).

These two species can be separated by the following characters: head sensillus $s 4$ present in P. trepostephanus sp. nov. (Fig. 27), but absent in P. sinensis sp. nov. (Fig. 21); female subgenital plate with flattened posterior margin in $P$. sinensis sp. nov. (Fig. 24), but with bulging posterior margin in P. trepostephanus sp. nov. (Fig. 30); male mesosome with extensive ventral plate in P. trepostephanus sp. nov. (Fig. 29), but without such a plate in P. sinensis sp. nov. (Fig. 23); central sternal plates present on abdominal segments II-VI in P. sinensis sp. nov. (Fig. 19), but only on segment VI in P. trepostephanus sp. nov. (Fig. 25); male subgenital plate with deep indentation posterior to setae, and with small accessory plate inside this indentation, in P. trepostephanus sp. nov. (Fig. 25), but without such an indentation or plate in $P$. sinensis sp. nov. (Fig. 19). 


\section{Etymology}

The specific epithet is derived from the type locality.

\section{Material examined}

\section{Holotype}

CHINA • ${ }^{\lambda}$; Guanxi Province, Jingxin County; 5 Oct. 2004; S.E. Bush leg.; ex Hemipus picatus capitalis; “ATP-2004-161, P-559”; NHMUK.

\section{Paratype}

CHINA $・ 1$; ; same collection data as for holotype; NHMUK.
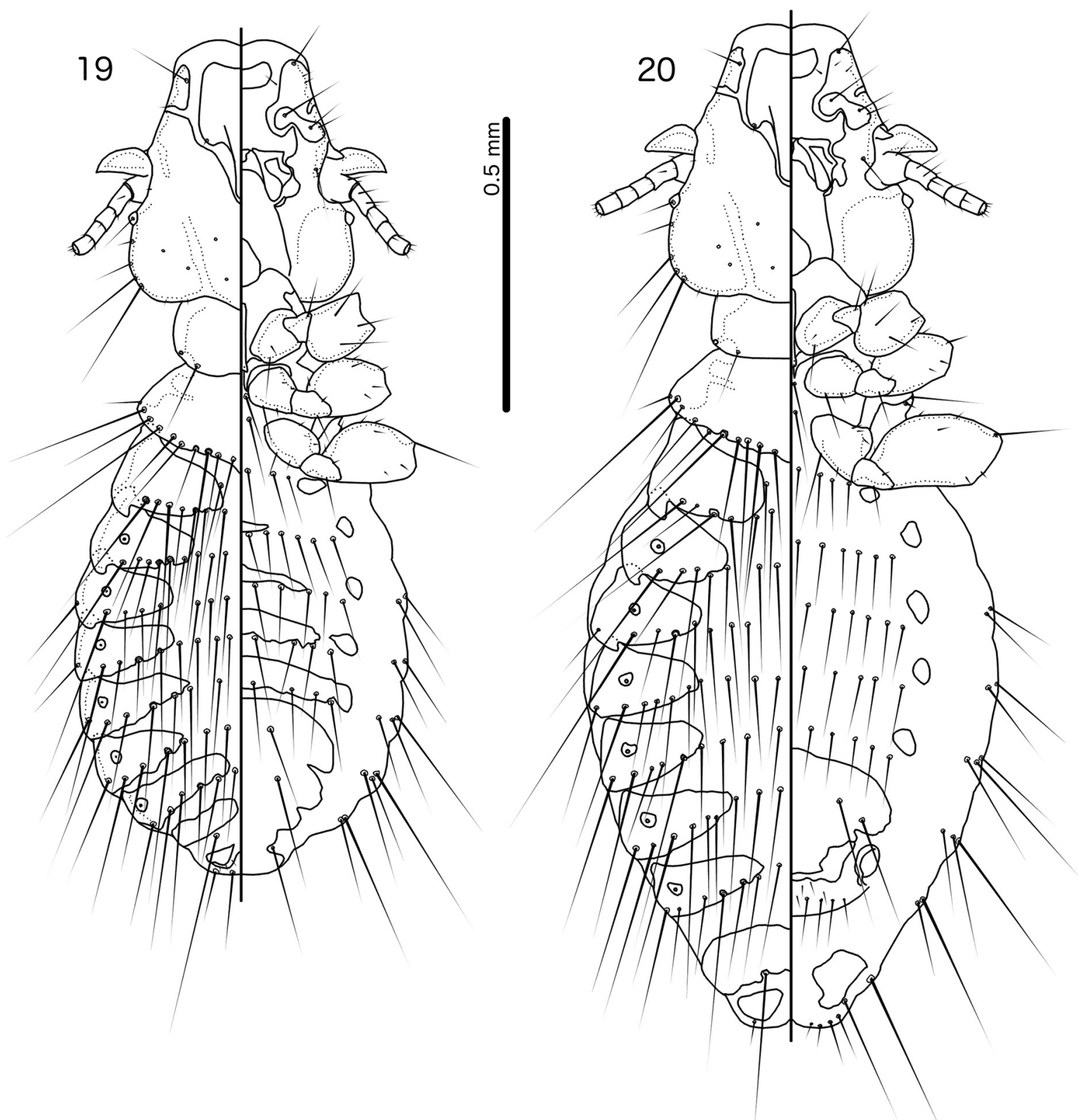

Figs 19-20. Philopterus sinensis sp. nov. ex Hemipus picatus capitalis (Horsfield, 1840). 19. Male habitus, dorsal and ventral views. 20. Female habitus, dorsal and ventral views. 


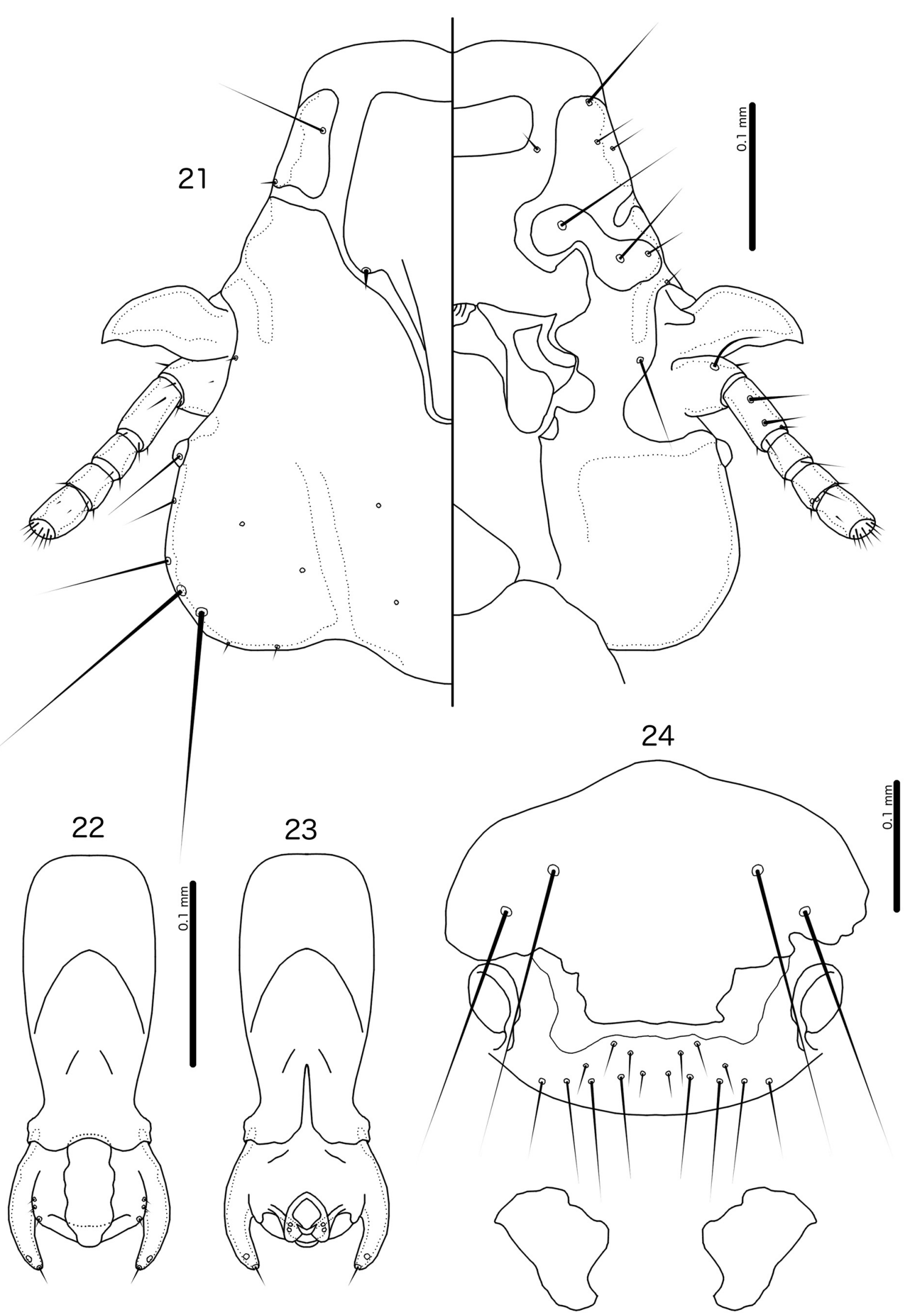

Figs 21-24. Philopterus sinensis sp. nov. ex Hemipus picatus capitalis (Horsfield, 1840). 21. Male head, dorsal and ventral views. 22. Male genitalia, dorsal view. 23. Male genitalia, ventral view. 24. Female subgenital plate, vulval margin, and subvulval plates, ventral view. 


\section{Type host}

Hemipus picatus capitalis (Horsfield, 1840) - bar-winged flycatcher-shrike (Vangidae).

\section{Description}

Head shape and chaetotaxy as in Fig. 21, preantennal area wide. Hyaline margin broad, not extending laterally beyond marginal carina, shallowly indented medianly. Dorsal anterior plate almost square, with broad, blunt posterior extension. Ventral anterior plate near-rectangular, wide and short, with slightly concave anterior margin. Coni small, curved slightly anteriorly. Gular plate small, irregular. Thoracic and abdominal segments as in Figs 19-20. Measurements as in Table 5.

\section{Male}

Thoracic and abdominal chaetotaxy as in Fig. 19 and Tables 2-4. Abdominal segment II without central sternal plate but with lateral accessory plates; segments III-V with small to wide central sternal plates and lateral accessory plate on each side; segment VI with wide central sternal plate fused to lateral accessory plates. Subgenital plate broad, lateral notches small, lateral sternal plate of segment IX+X fused to subgenital plate. Basal apodeme broad (Figs 22-23), constricted in distal half. Mesosomal thickening oblong, irregular; 3 microsetae on each side of mesosome. Gonopore with convergent anterior margin and bulbous distal extensions (Fig. 23), 2 sensilla on each side of gonopore. Parameres fused to basal apodeme, long, slender; pst1-2 as in Figs 22-23.

\section{Female}

Thoracic and abdominal chaetotaxy as in Fig. 20 and Tables 2-4. Central sternal plates absent, lateral accessory plates present on segments II-VI. Subgenital plate and vulval margin as in Fig. 24, chaetotaxy as in Fig. 24 and Table 3. Subvulval plates partially obscured by gut content, but appear to be broad, blunt distally.

\section{Philopterus trepostephanus sp. nov. urn:1sid:zoobank.org:act:BA72A2B0-545C-434F-8820-152AB279A3CA}

Figs 25-30; Tables 2-5

\section{Diagnosis}

Apart from the similarity between Philopterus trepostephanus sp. nov. and P. sinensis sp. nov. outlined under the latter species (see above), P. trepostephanus sp. nov. does not appear to be morphologically close to any other known species of the genus. The species morphologically closest to $P$. trepostephanus sp. nov. may be P. petrescuae Adam in Sychra et al., 2011 (ex Dicrurus hottentottus (Linnaeus, 1766)). These two species share the following characters: hyaline margin extends lateral to as 1 (Fig. 27); ventral sclerite of male mesosome with lateral extensions (Fig. 29); long vulval setae far anterior to the vulval margin (Fig. 30); gonopore extensive, collar-shaped. These two species can be separated by the following characters: lateral extensions of ventral mesosomal sclerite in distal half in P. trepostephanus sp. nov. (Fig. 29), but in proximal half in P. petrescuae, and the overall shape of this sclerite also differs between these species; coni with recurving anterior 'hooks' in $P$. petrescuae, but without such hooks in P. trepostephanus sp. nov. (Fig. 27); central sternite absent on male abdominal segment VI in P. petrescuae, but present in P. trepostephanus sp. nov. (Fig. 25); lateral lobes of hyaline margin more extensive in P. petrescuae than in P. trepostephanus sp. nov. (Fig. 27); dorsal anterior plate (ignoring posterior extension) longer than wide in $P$. petrescuae, but about as wide as long in $P$. trepostephanus sp. nov. (Fig. 27); macrosetae of female subgenital plate all situated on plate in P. trepostephanus sp. nov. (Fig. 30), but lateral setae on each side situated lateral to plate in P. petrescuae.

\section{Etymology}

The species name is constructed from 'trepo', Greek for 'I turn', and 'stephanos', Greek for 'crown, wreath'. This refers to the shape of the gonopore, with its anterio-lateral hooks. 


\section{Material examined}

Holotype

THAILAND • đ'; Songkhla Province, Muang, Thung Wang; 4 Sep. 1963; W. Songprakob [as Songphabob] and W. Suwan Laong leg.; ex Tephrodornis virgatus fretensis; "WS-471"; NHMUK.

\section{Paratypes}

THAILAND $\bullet ~ 19$; same collection data as for holotype; NHMUK $\bullet 1$; same collection data as for holotype; PIPR.

\section{Non-type material}

THAILAND • 3 $\widehat{\jmath}, 3$ 우 ; Loei Province, Thali, Ban Muang Khai; 26 Jan. 1955; R.E. Elbel leg.; ex Tephrodornis virgatus mekongensis; "RE-4564, RT-B-31145”; PIPR • 1 $\AA, 1$ q; same collection data as for preceding; "RE-4563, RT-B-31144"; PIPR.

\section{Type host}

Tephrodornis virgatus fretensis Robinson \& Kloss, 1920 - large woodshrike (Vangidae).

\section{Other host}

Tephrodornis virgatus mekongensis Meyer de Schauensee, 1946.

\section{Description}

Head shape and chaetotaxy as in Fig. 27, preantennal area broad. Hyaline margin broad, extending laterally beyond marginal carina, shallowly concave medianly. Dorsal anterior plate roughly quadratic, with shallowly concave anterior margin and broad posterior extension. Ventral anterior plate roughly semicircular, with slightly concave anterior margin. Coni moderate, slender, pointed posteriorly. Gular plate large. Thoracic and abdominal segments as in Figs 25-26. Measurements as in Table 5.

\section{Male}

Thoracic and abdominal chaetotaxy as in Fig. 25 and Tables 2-4. Central sternal plates absent on segments II-V, present and broad on segment VI. Lateral accessory plates present on segments II-VI. Subgenital plate broad anteriorly, narrowing markedly on segment IX $+X$, widening distally; lateral accessory plates present on abdominal segment IX $+\mathrm{X}$, of about same size as other lateral accessory plates. Basal apodeme short, slender, constricted at mid-length (Figs 28-29). Mesosomal thickening long, rounded anteriorly, with slight lateral bulges. Mesosome with 3 microsetae on each side (Fig. 28). Gonopore as in Fig. 29, broad and with prominent distal lobes; 2 microsetae on each side of gonopore. Parameres elongated, slender; pst1-2 as in Figs 28-29.

\section{Female}

Thoracic and abdominal chaetotaxy as in Fig. 26 and Tables 2-4. Central sternal plates absent on segments II-VI. Lateral accessory plates present on segments II-VI. Subgenital plate and vulval margin as in Fig. 30, chaetotaxy as in Fig. 30 and Table 3. Subvulval plates broad.

\section{Remarks}

Specimens from the two host subspecies differ slightly in head shape and size (specimens from Tephrodornis virgatus mekongensis are generally larger than specimens from T. v. fretensis; Table 5) and abdominal chaetotaxy (specimens from T. v. mekongensis typically have more tergal setae per segment than those from $T$. v. fretensis), but some specimens from T. v. mekongensis have the same abdominal chaetotaxy as material from the type host subspecies, and most measurements overlap somewhat. The 


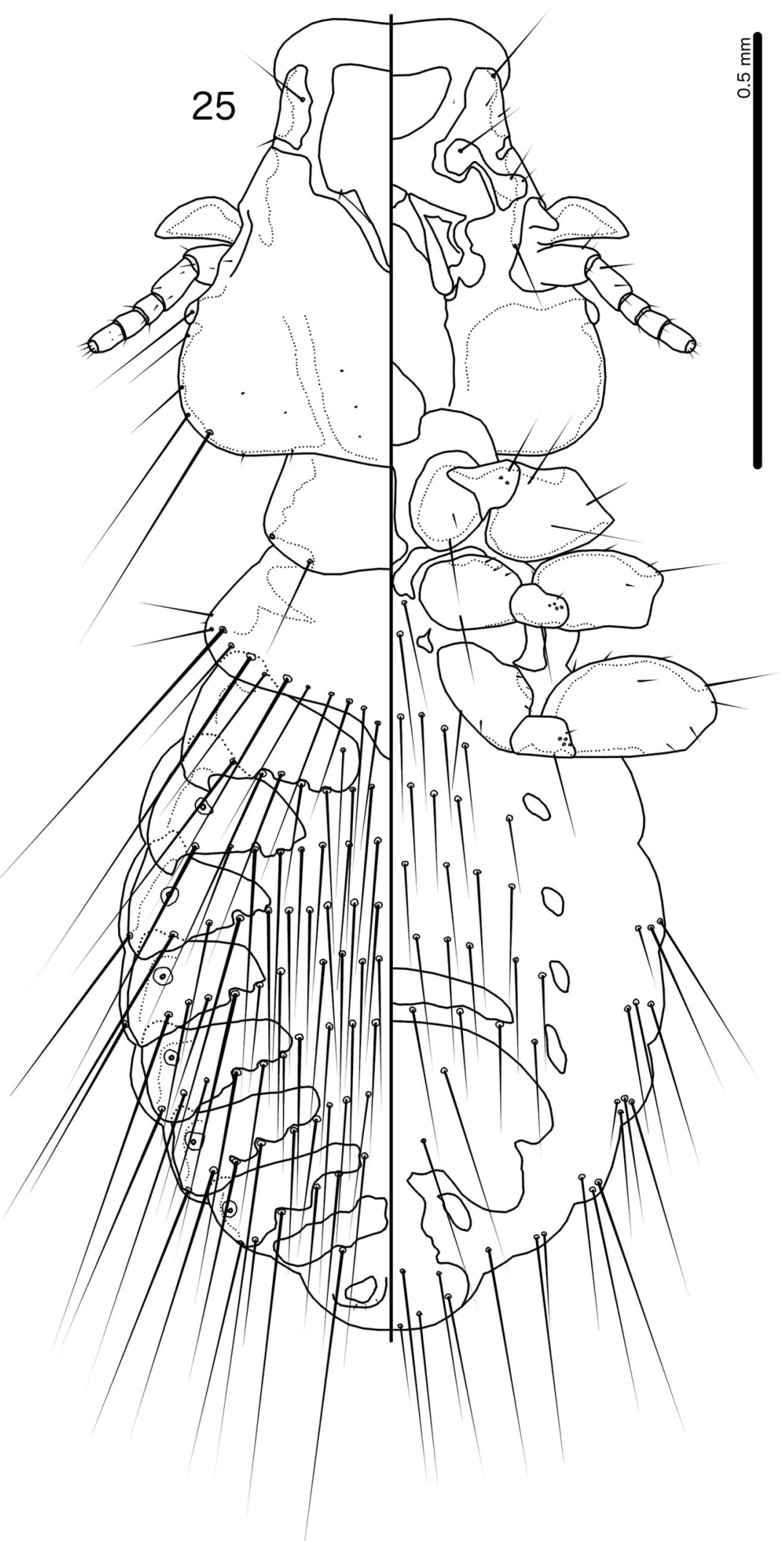

Fig. 25. Philopterus trepostephanus sp. nov. ex Tephrodornis virgatus fretensis Robinson \& Kloss, 1920, male habitus, dorsal and ventral views. 


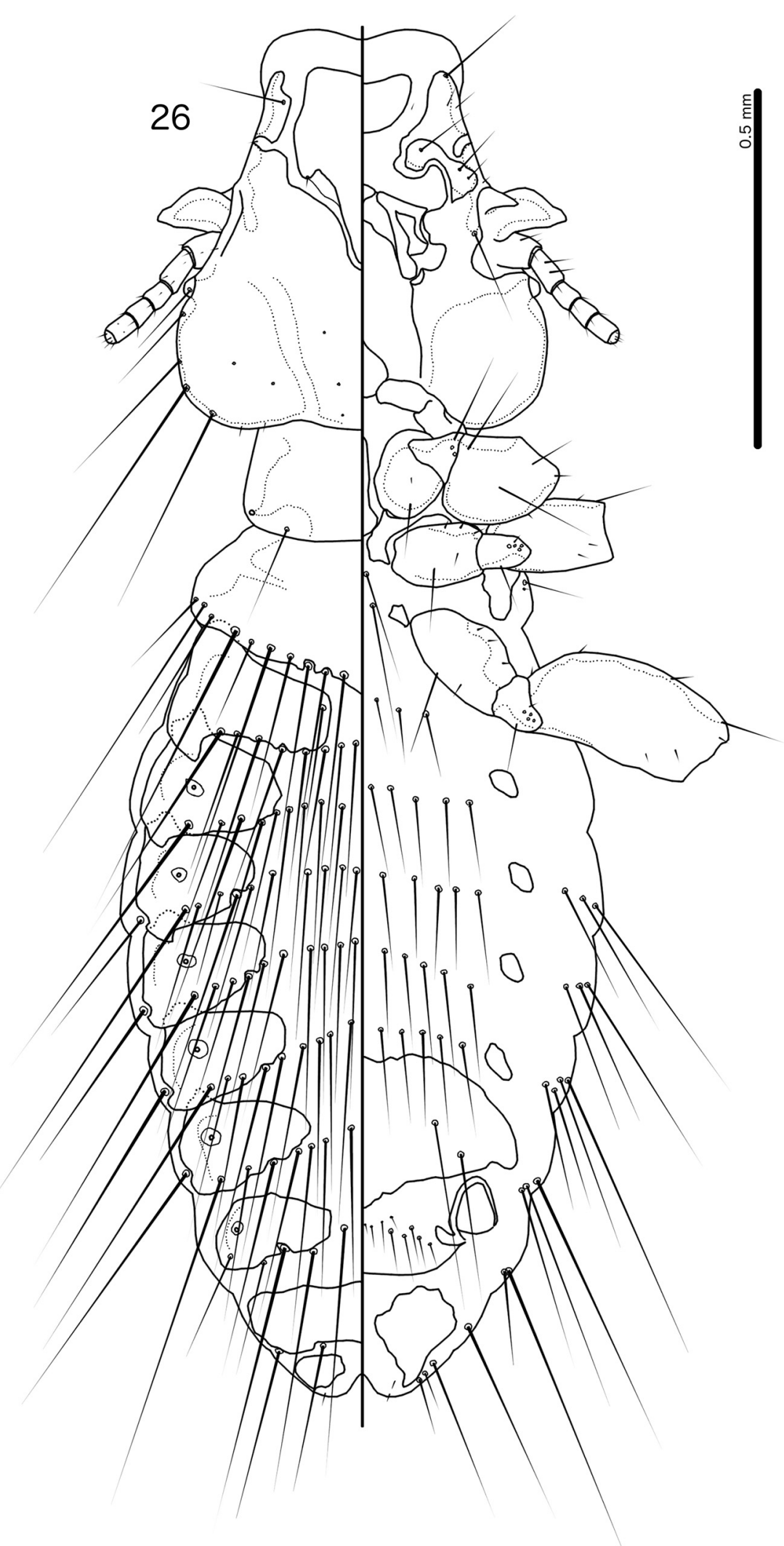

Fig. 26. Philopterus trepostephanus sp. nov. ex Tephrodornis virgatus fretensis Robinson \& Kloss, 1920, female habitus, dorsal and ventral views. 


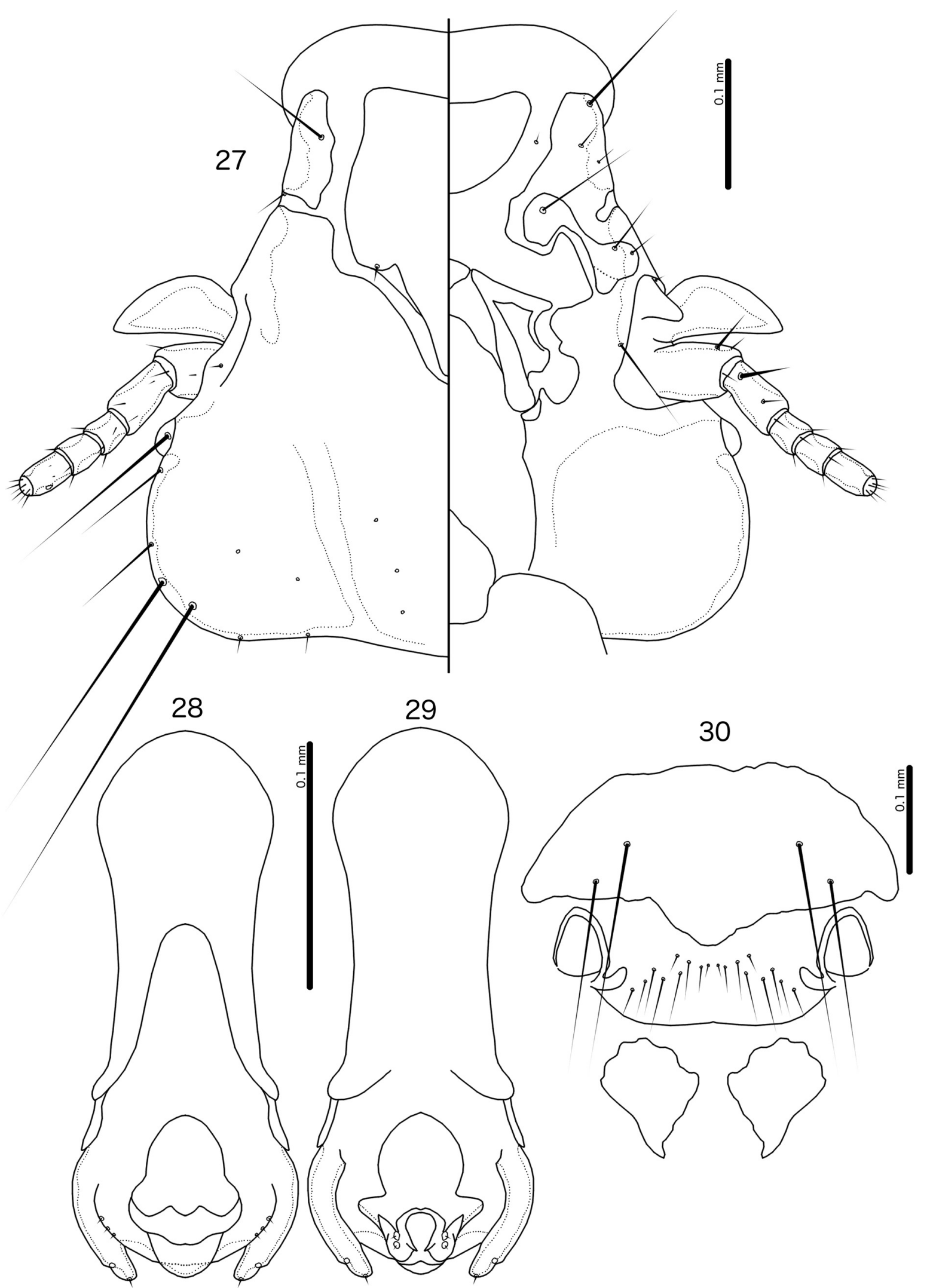

Figs 27-30. Philopterus trepostephanus sp. nov. ex Tephrodornis virgatus fretensis Robinson \& Kloss, 1920. 27. Male head, dorsal and ventral views. 28. Male genitalia, dorsal view. 29. Male genitalia, ventral view. 30. Female subgenital plate, vulval margin, and subvulval plates, ventral view. 
ranges of the two known host subspecies are separated by a gap in distribution in peninsular Thailand (Robson 2006). We tentatively consider all specimens from both host subspecies conspecific.

Philopterus stansburyensis sp. nov. urn:lsid:zoobank.org:act:DB198892-3BCC-4D00-988C-EAFE8E446B7A

Figs 31-36; Tables 2-4, 6

\section{Diagnosis}

The only previously known species of Philopterus from a cardinalid host is P. cardinalis Piaget, 1880 (ex Paroaria coronata (Miller, 1776)); this species is poorly described and illustrated, and has never been redescribed. We have examined 3 specimens $(1 \hat{0}, 2$ o 9 ) collected by Piaget and labeled as P. cardinalis (NHMUK 010712725-27); however, none of them is in good enough condition to allow proper morphological redescription. An adequate comparison between $P$. cardinalis and $P$. stansburyensis sp. nov. must await the redescription of new specimens of $P$. cardinalis.

The male genitalia of $P$. stansburyensis sp. nov. and the absence of sternal plates in the Colorado specimens resemble conditions in P. confusio Ansari, 1955 (ex Turdus fulviventris Sclater, 1857). These two species can be separated by the following characters: the posterior projection of dorsal anterior plate short and narrow (shorter than the plate itself) in male of P. stansburyensis sp. nov. (Fig. 33), but long and wide (longer than the plate itself) in male of $P$. confusio (Ansari 1955: fig. 7a); lateral slits separating sternites VII and VIII of male subgenital plate long, reaching almost to setal apertures in P. stansburyensis sp. nov. (Fig. 31), but short, just slightly cut out from lateral margin of plate in P. confusio (Ansari 1955: fig. 7c); female subgenital accessory plates oval or pear-shaped, pointed anteriorly in $P$. stansburyensis sp. nov. (Fig. 36), but horizontally elongated, pointed medioposteriorly in P. confusio (Ansari 1955: fig. 7f); vulval setae become shorter medianly and are placed in one row in $P$. stansburyensis sp. nov. (Fig. 36), but all are short and placed in two rows in P. confusio (Ansari 1955: fig. 7g). Note that all these comparisons are based on illustrations given by Ansari (1955), which may be of limited reliability.

\section{Etymology}

The specific name is derived from the type locality.

\section{Material examined}

\section{Holotype}

USA - 3 ; Utah, Tooele County, Stansbury Mountains, Hickman Canyon; alt. 7000 ft [2134 m]; 24 Jun. 1969; ex Pheucticus melanocephala melanocephala; "09084”; NHMUK.

\section{Paratypes}

USA 11 ग 3 , 9 q ; Colorado; 1967; J.A. Allen leg.; same host as for holotype; mounted by R.C. Dalgleish; “1367”; USNM.

\section{Type host}

Pheucticus melanocephalus melanocephalus (Swainson, 1827) - black-headed grosbeak (Cardinalidae).

\section{Description}

Head shape and chaetotaxy as in Fig. 33, preantennal area broad. Hyaline margin wide, extending laterally beyond marginal carina. Dorsal anterior plate as in Fig. 33. Ventral anterior plate semi-circular, with slightly concave anterior margin. Coni large, blunt, with round posterior margins, pointing posterolaterally. Gular plate small and narrowly pointed, displaced anteriorly. Thoracic and abdominal segments and chaetotaxy as in Figs 31-32 and Tables 2-4. Measurements as in Table 6. 


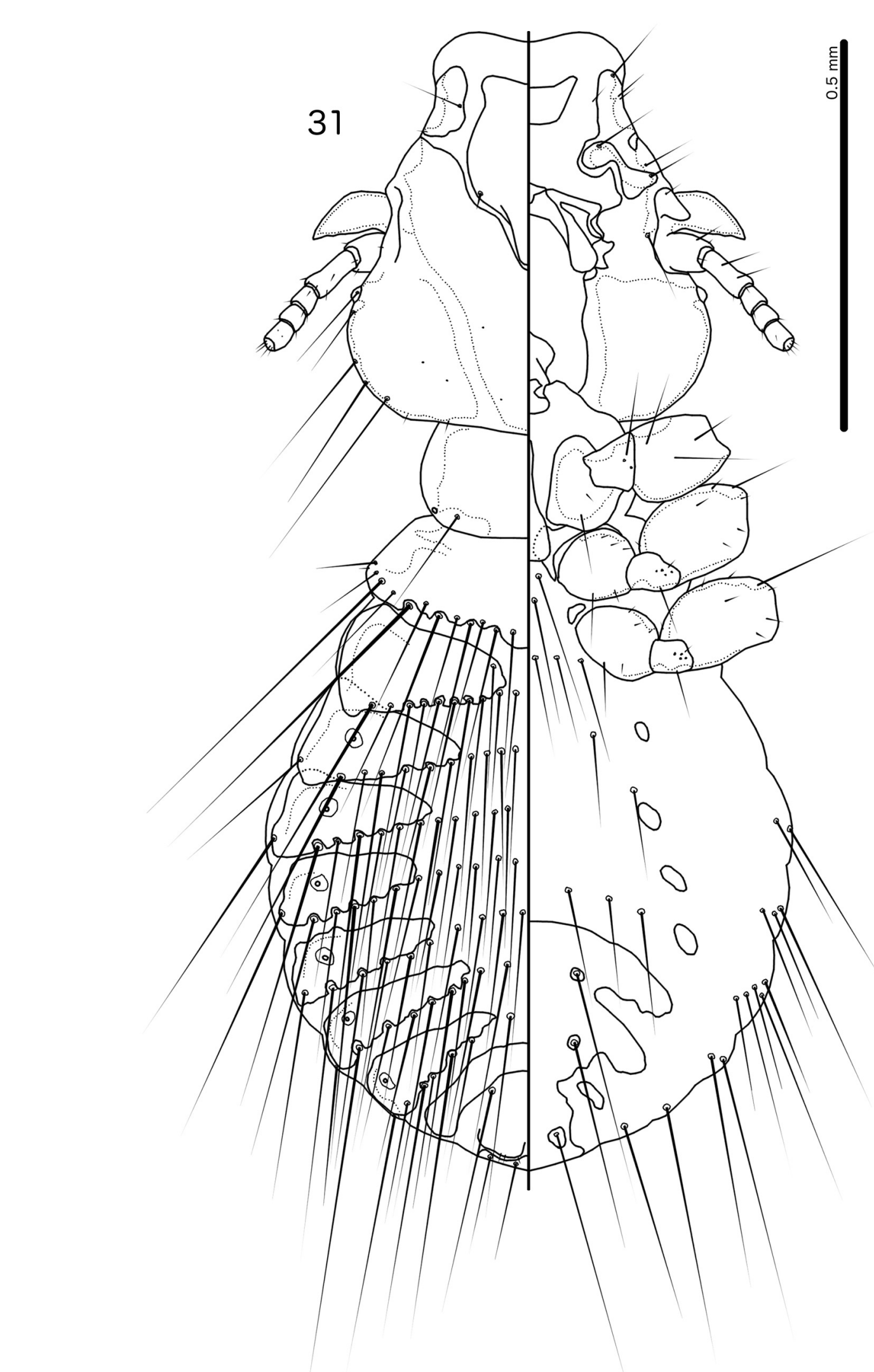

Fig. 31. Philopterus stansburyensis sp. nov. ex Pheucticus melanocephalus melanocephalus (Swainson, 1827), male habitus, dorsal and ventral views. 


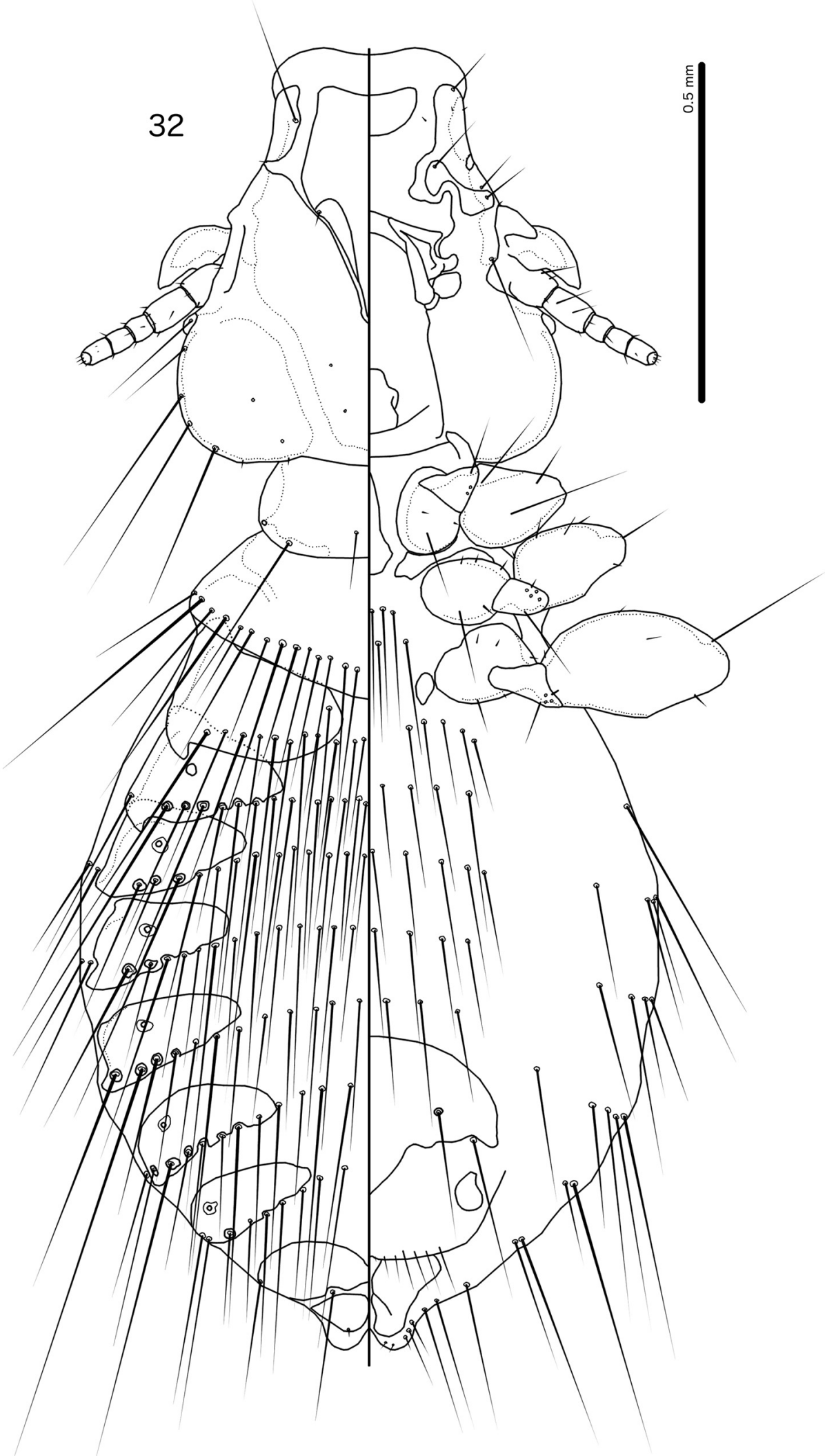

Fig. 32. Philopterus stansburyensis sp. nov. ex Pheucticus melanocephalus melanocephalus (Swainson, 1827), female habitus, dorsal and ventral views. 


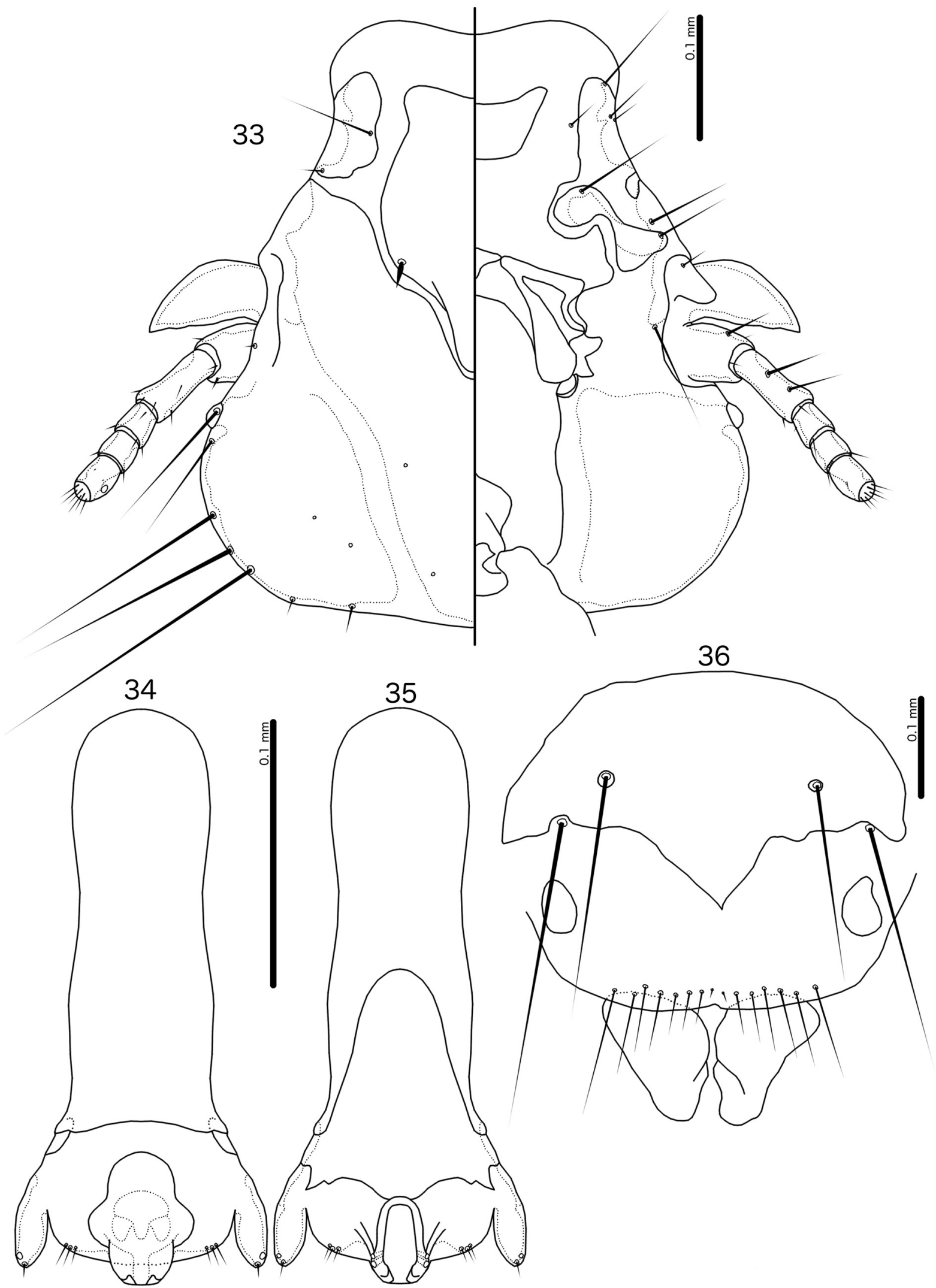

Figs 33-36. Philopterus stansburyensis sp. nov. ex Pheucticus melanocephalus melanocephalus (Swainson, 1827). 33. Male head, dorsal and ventral views. 34. Male genitalia, dorsal view. 35. Male genitalia, ventral view. 36. Female subgenital plate, vulval margin, and subvulval plates, ventral view. 


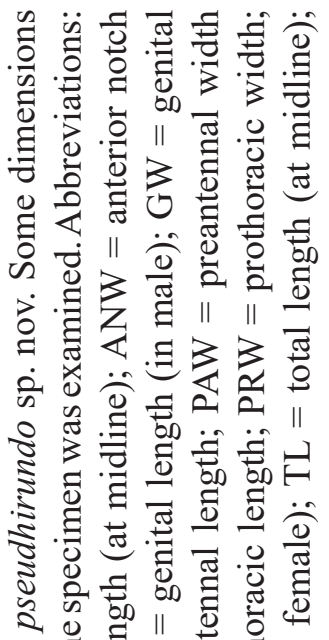

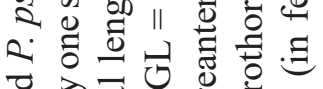

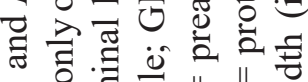
字氙产

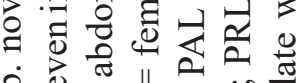

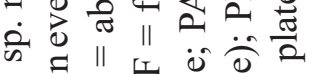

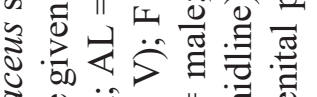

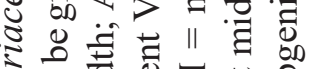

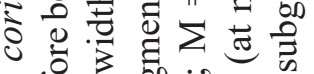

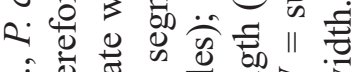

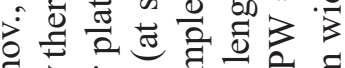

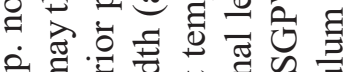

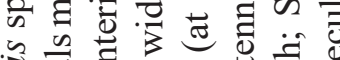

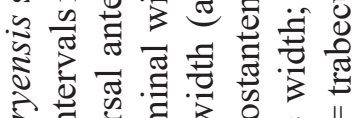

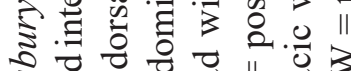
है

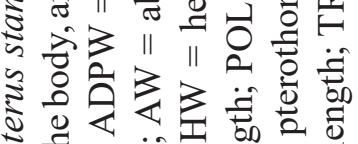

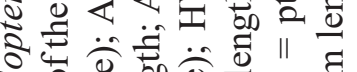

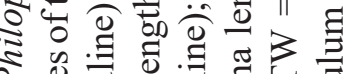

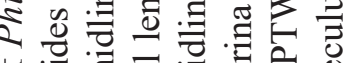

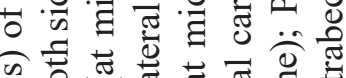
के

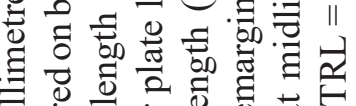

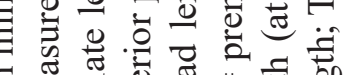

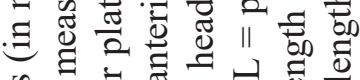

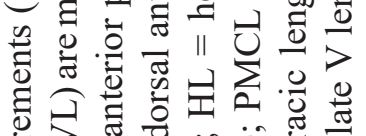

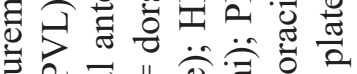

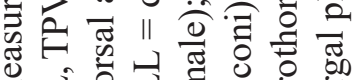

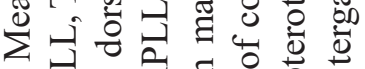

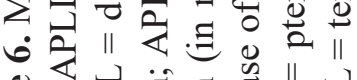

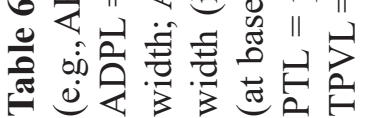

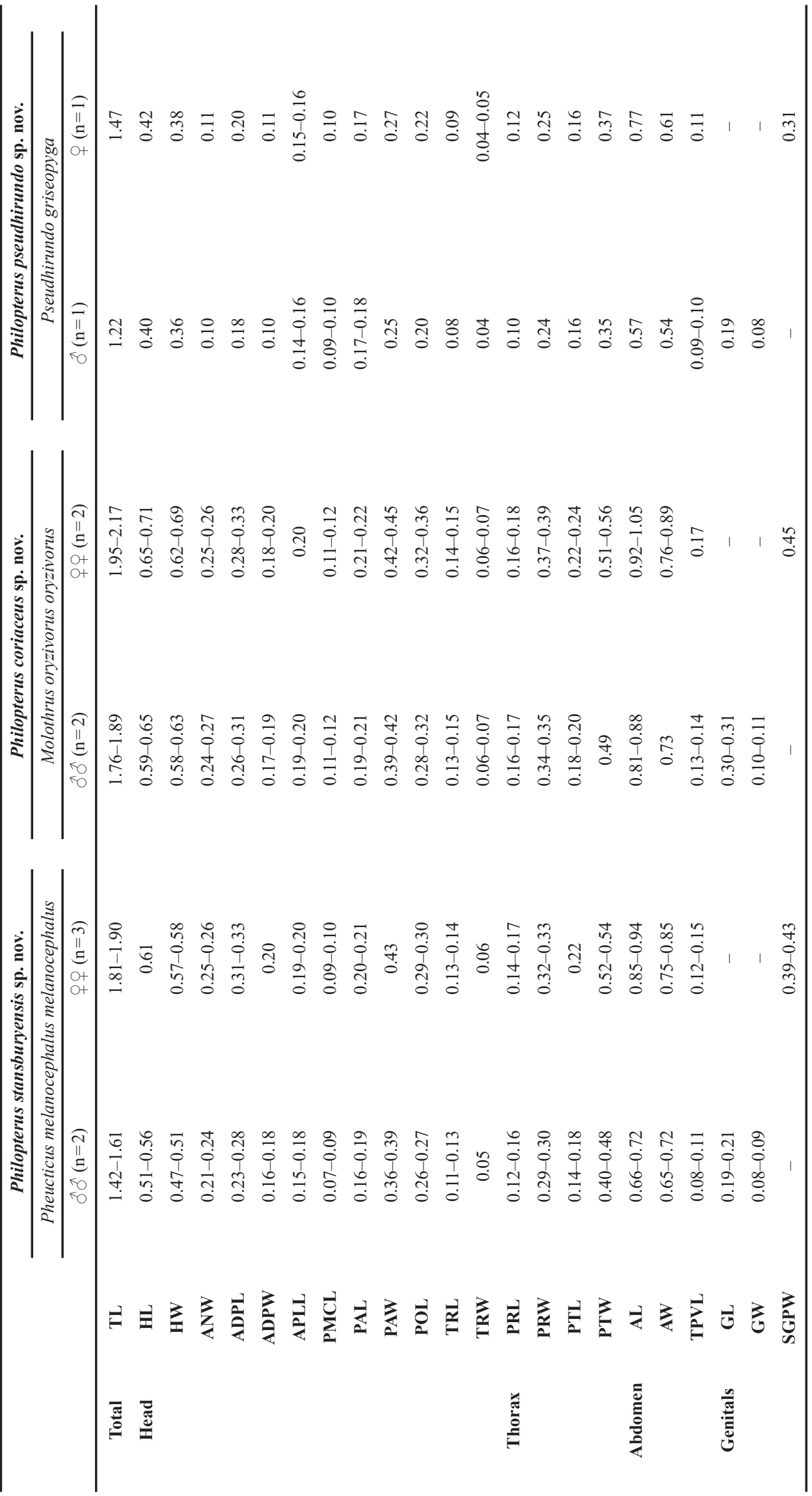




\section{Male}

Thoracic and abdominal chaetotaxy as in Fig. 31 and Tables 2-4. Tergite IX+X medianly continuous. Central sternal plates absent on segments II-VI. Holotype with lateral accessory sternal plates on each side of segments III-VI, but in specimens from Colorado these lateral accessory sternal plates not visible. Subgenital plate with deep lateral notches and elongated lateral accessory plate on segment IX + X. Basal apodeme long, slender (Figs 34-35). Mesosomal thickening diffuse, with wide extensions distally; 3 microsetae on each side of mesosome. Gonopore elongate, rounded (Fig. 35), with 2 sensilla on lateral margins near distal ends. Parameres completely fused to basal apodeme, slender, with pst1-2 as in Figs 34-35.

\section{Female}

Thoracic and abdominal chaetotaxy as in Fig. 32 and Tables 2-4. Gular plate trilobal, with blunt anterior margin. Central sternal plates absent on segments II-VI. Lateral accessory sternal plates not visible. Subgenital plate and vulval margin as in Fig. 36, lateral accessory plates on segment IX+X small and oval. Vulval chaetotaxy as in Fig. 36 and Table 3; vulval setae longest laterally, gradually shortening medianly, with minute median pair. Subvulval plates broadly triangular, with rounded anterior margin.

Philopterus coriaceus sp. nov.

urn:lsid:zoobank.org:act:8D76847E-153C-4061-B476-420FEED3C483

Figs 37-42; Tables 2-4, 6

\section{Diagnosis}

Finding the closest known relative of Philopterus coriaceus sp. nov. is difficult. This species is set apart from almost all other known Philopterus complex species by the presence of a pair of setae on the anterior margin of female tergopleurite IX $+\mathrm{X}$. To our knowledge, this seta is only present in some species of Mayriphilopterus Mey, 2004. All of the species in this genus are Neotropical, but none of them occur on passeriforms.

However, P. coriaceus sp. nov. does not key to Mayriphilopterus in the key of Mey (2004), and can be separated from this genus by the following characters: coni present in P. coriaceus sp. nov. (Fig. 39), but absent (possibly highly reduced) in Mayriphilopterus; hyaline margin with thickened setae in Mayriphilopterus, but without such setae in P. coriaceus sp. nov. (Fig. 39); area between subgenital plate and vulval margin with a large number of small setae in Mayriphilopterus, but without such setae in $P$. coriaceus sp. nov. (Fig. 42). It thus seems unlikely that $P$. coriaceus sp. nov. is closely related to Mayriphilopterus.

Only two species of Philopterus are previously known from icterid hosts: Philopterus quiscali Osborn, 1896 (ex Quiscalus quiscula (Linnaeus, 1758)) and Philopterus agelaii Osborn, 1896 (ex Agelaius phoeniceus (Linnaeus, 1766)). No detailed descriptions or illustrations of either of these species have been published, and both species are in need of redescription.

From Osborn's descriptions of both species, and the illustration of $P$. quiscali ( $P$. agelaii not illustrated in Osborn 1896, but said to be similar to P. quiscali), these two species can be separated from P. coriaceus sp. nov. by the following characters: preantennal head proportionately wider in $P$. quiscali than in P. coriaceus sp. nov. (Fig. 39); dorsal anterior plate with broad posterior extension in P. quiscali, but with slender posterior extension in P. coriaceus sp. nov. (Fig. 39); tergopleurites of P. quiscali extending only about halfway to midline of abdomen on each side, whereas those of $P$. coriaceus sp. nov. are much longer in both sexes, almost reaching midline in more posterior segments in male. Chaetotaxy is not given for either $P$. quiscali or $P$. agelaii, but Osborn's illustration of $P$. quiscali has only apertures for 6 setae illustrated on each of the tergopleurites of segment II. In P. coriaceus sp. nov. there are 8 setae placed on each of the tergopleurites of this segment in both sexes (Figs 37-38); however, the number of 


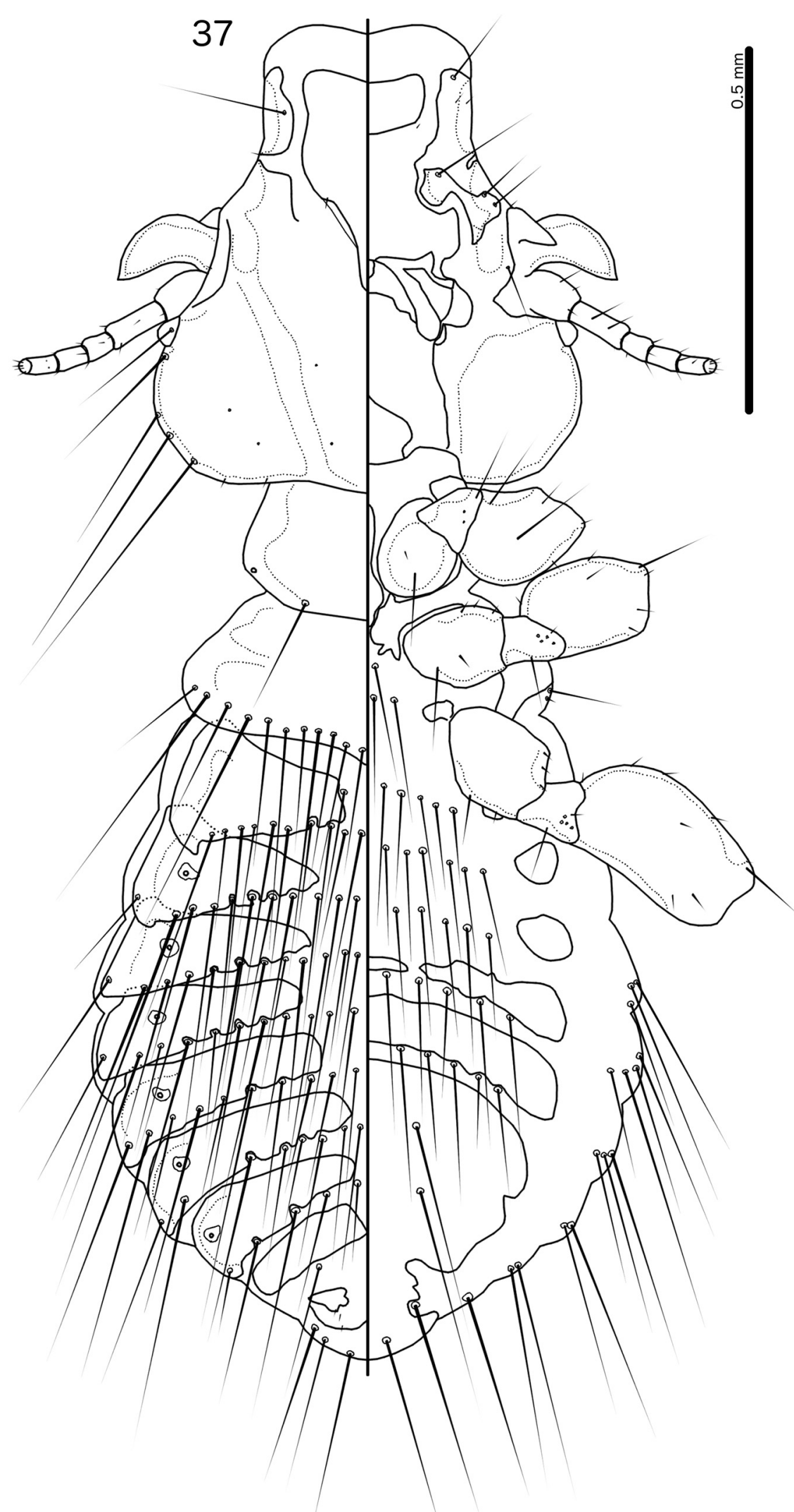

Fig. 37. Philopterus coriaceus sp. nov. ex Molothrus oryzivorus oryzivorus (Gmelin, 1788), male habitus, dorsal and ventral views. 


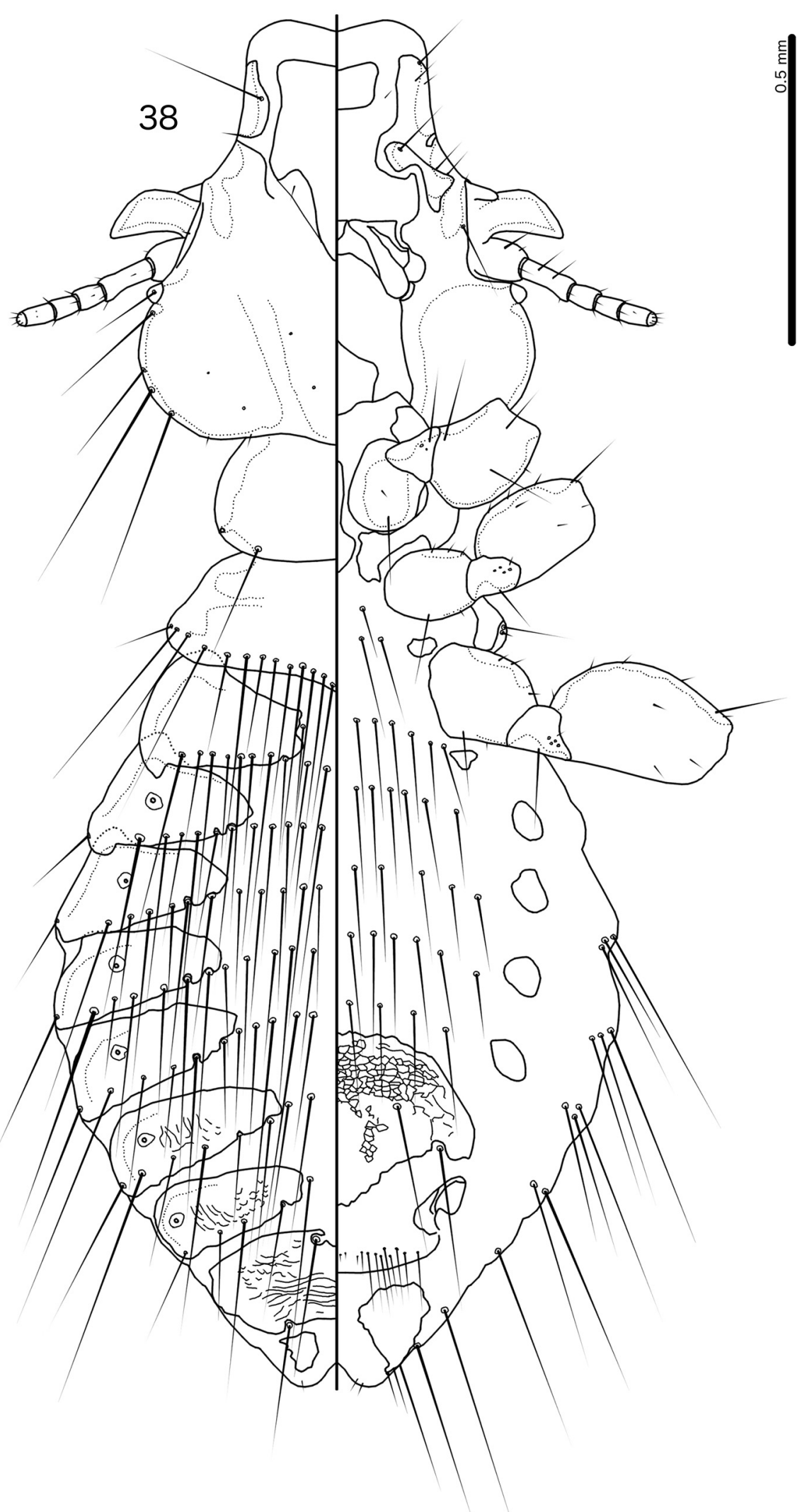

Fig. 38. Philopterus coriaceus sp. nov. ex Molothrus oryzivorus oryzivorus (Gmelin, 1788), female habitus, dorsal and ventral views. 
setae situated median to the tergopleurites in $P$. quiscali is unknown. In specimens of $P$. agelaii deposited at the NHMUK, there are 7-8 setae on each side in females and 8-9 setae on each side in males, which overlap with the number of setae in $P$. coriaceus sp. nov.; one seta on each side is situated median to the tergopleurites in both sexes of the NHMUK specimens of $P$. agelaii. In addition, Osborn (1896: 220) mentioned "brown spots on each segment back to the eighth $[=\mathrm{IX}+\mathrm{X}]$; those on the sixth segment $[=\mathrm{VII}]$ form the outer portion of the genital patch." Osborn (1896) further stated that the "lateral spots" of $P$. agelaii are "small, rather elongated, oblique"; it is not clear whether he was describing the male or the female, but his illustration is of a male. We interpret these spots as the overlap of the median section of the tergopleurites with either the lateral accessory sternal plates (in segments II-VI) or the subgenital plate (segments VII-XI+X). This overlap often shows as darker brown spots than the rest of the tergopleurite. This suggests that the central sternal plates are absent on segments II-VI in P. quiscali and $P$. agelaii, whereas these are present on male segments V-VII in P. coriaceus sp. nov. (Fig. 37).

\section{Etymology}

The specific name is derived from Latin 'coriaceo' for 'leather-like', referring to the colour and texture of the abdominal plates.

\section{Material examined}

\section{Holotype}

PERU $-\hat{O}$ (marked with black dot on slide); Hacienda Amazonia, near Atalaya, Department of Madre de Dios; 4 Nov. 1985; S.M. Lanyon leg.; ex Molothrus oryzivorus oryzivorus (as Scaphidura oryzivora); “1032”; NHMUK.

\section{Paratypes}

PERU・ 1 ภ, 2 우; same collection data as for holotype; NHMUK.

\section{Type host}

Molothrus oryzivorus oryzivorus (Gmelin, 1788) - giant cowbird (Icteridae).

\section{Description}

Head shape and chaetotaxy as in Fig. 39, preantennal area broad. Hyaline margin broad, shallowly concave medianly, extending laterally slightly beyond marginal carina. Dorsal preantennal plate narrowing gently posteriorly, ads situated in transparent section. Ventral anterior plate roughly trapezoidal, anterior margin concave. Coni long, broad, pointed posteriorly. Gular plate large, irregular. Thoracic and abdominal segments as in Figs 37-38. Measurements as in Table 6.

\section{Male}

Thoracic and abdominal chaetotaxy as in Fig. 37 and Tables 2-4. Tergopleurite VIII interrupted medianly. Central sternal plates absent from segments II-IV, present but fragmented on segment V, and present on segment VI. Lateral accessory plates present on segments II-IV, present and fused to central sternal plates on segments V-VI. Subgenital plate large, lateral incisions shallow or absent, lateral accessory plate of segment IX $+X$ fused to subgenital plate. Basal apodeme long, rectangular (Figs 40-41). Mesosomal thickening about as broad as long, laterally pointed on dorsal side, with roughly crescentshaped sclerotization in anterior end and triangular sclerotization centrally; 3 microsetae on each side of mesosome. Gonopore bilobed anteriorly, distal part as in Fig. 41. Parameres short, stocky (Figs 40-41); pst $1-2$ as in Figs 40-41.

\section{Female}

Thoracic and abdominal chaetotaxy as in Fig. 38 and Tables 2-4. Tergopleurites VI-IX+X with slight to extensive reticulation median to spiracle openings. Central sternal plates absent on segments 


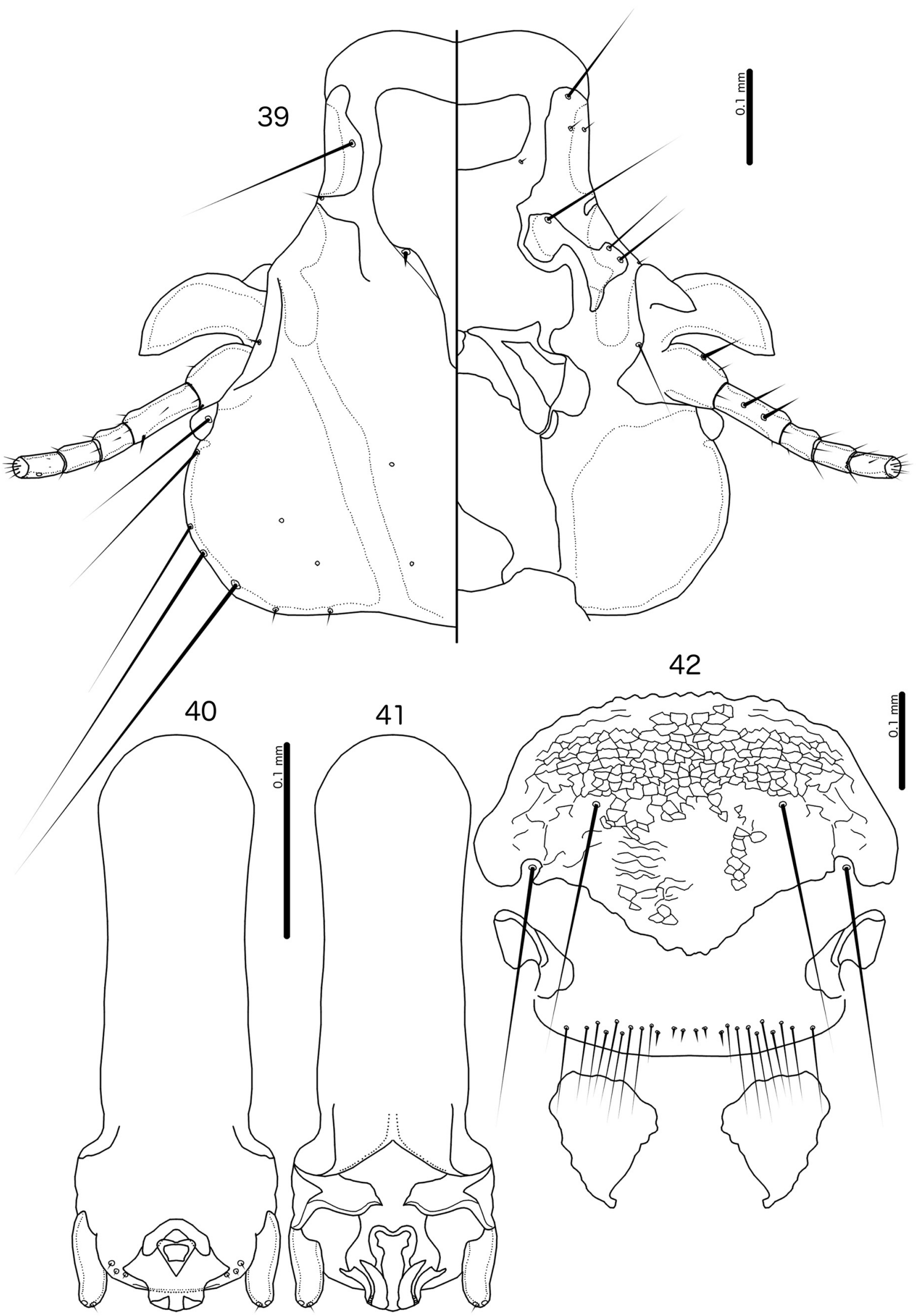

Figs 39-42. Philopterus coriaceus sp. nov. ex Molothrus oryzivorus oryzivorus (Gmelin, 1788). 39. Male head, dorsal and ventral views. 40. Male genitalia, dorsal view. 41. Male genitalia, ventral view. 42. Female subgenital plate, vulval margin, and subvulval plates, ventral view. 
II-VI. Lateral accessory plates present on segments II-VI. Subgenital plate as in Fig. 42, reticulation prominent. Lateral sclerotizations of vulval area extended to vulval margin, chaetotaxy as in Fig. 42 and Table 3; short vulval setae thorn-like. Subvulval plates broad, roughly triangular, each with small postero-median projection.

\section{Remarks}

Philopterus coriaceus sp. nov. is only the third species of Philopterus described from icterid hosts. This is surprising, as hosts in this family have been examined extensively, and many other species of ischnoceran lice are known from icterid hosts (e.g., Cicchino 1990, 2004; Cicchino \& Castro 1996; Valim \& Palma 2012). However, two previous studies have found comparatively low infestation rates of Philopterus on icterid hosts: $11.5 \%$ of examined red-winged blackbirds, Agelaius phoeniceus (Linnaeus, 1766) (Spory 1965) and 4.1\% of brown-headed cowbirds, Molothrus ater (Boddaert, 1783) (Hahn et al. 2000).

The lack of records of Philopterus complex lice on icterid hosts may be related to the presence of lice of the genus Bizarrifrons Eichler, 1938 on some icterid hosts. This genus belongs to the Brueelia complex (Valim \& Palma 2012; Gustafsson \& Bush 2017) and is also considered to belong to the 'head louse ecomorph'. Competition may influence the distribution of these lice, but more ecological information is needed to assess any potential interactions between these species.

Both $P$. agelaii and $P$. quiscali are in need of redescription before an adequate comparison between these species and $P$. coriaceus sp. nov. can be made. It is not clear what gender of $P$. quiscali was described by Osborn (1896); however, Emerson (1960) noted that only one female and a nymph are present in Osborn's collection at Ohio State University, Columbus, Ohio. Emerson (1960) designated the female as the lectotype, stating that a female was illustrated. This seems incorrect, as the illustrated specimen has a rounded terminal abdomen and no medianly continuous tergopleurite, suggesting that it is a male. If so, the illustrated male is likely lost.

\section{Philopterus pseudhirundo sp. nov. urn:1sid:zoobank.org:act:5D816C2B-A805-4804-ABEB-9C90AC672D3F}

Figs 43-48; Tables 2-4, 6

\section{Diagnosis}

Philopterus pseudohirundo sp. nov. belongs to the same group as other species of Philopterus known from hirundinid hosts (see Table 7). Of these, only P. excisus Nitzsch, 1818 (ex Delichon urbicum (Linnaeus, 1758)), and P. microsomaticus Tandan, 1955 (ex Hirundo rustica rustica Linnaeus, 1758), were illustrated and described in sufficient detail for an adequate comparison to be made. Characters supporting this relationship include the strongly bilobed hyaline margin (Fig. 45), the somewhat splayed distal male genitalia (Figs 46-47), and the general shape of the head (Fig. 45).

Philopterus pseudhirundo sp. nov. can be separated from P. excisus by the following characters (see Tandan (1955) and Clay \& Hopkins (1960) for partial illustrations and redescriptions of $P$. excisus): preantennal area longer and narrower in P. pseudhirundo sp. nov. than in P. excisus; abdominal segments $\mathrm{IV}-\mathrm{V}$ in male $P$. excisus with 6-8 pleural setae on each side, but with only 4-5 pleural setae on each side in P. pseudhirundo sp. nov. (Fig. 43); male sternal plate V interrupted medianly in P. excisus, but medianly continuous in $P$. pseudhirundo sp. nov.; distal margin of male genitalia (ignoring gonopore) convex in P. excisus, but concave in P. pseudhirundo sp. nov. (Figs 46-47); mesosome with wide angular lateral margins in $P$. excisus, but with slender rounded lateral margins in $P$. pseudhirundo sp. nov. (Fig. 47); parameres reach about as far distally as mesosome in P. excisus, but much father distally in 
P. pseudhirundo sp. nov. (Figs 46-47); anterior end of mesosome in P. excisus different in shape from that of $P$. pseudhirundo sp. nov. (Fig. 46).

Philopterus pseudhirundo sp. nov. can be separated from P. microsomaticus by the following characters: male tergopleurite II with 4-7 (typically 6) setae on each side in P. microsomaticus, but with 8 setae on each side in P. pseudhirundo sp. nov. (Fig. 43); male genitalia with concave distal margin (ignoring gonopore) in P. pseudhirundo sp. nov. (Figs 46-47), but with protruding distal end in P. microsomaticus; mesosome protruding distally to parameres in P. microsomaticus, but not in P. pseudhirundo sp. nov. (Figs 46-47); anterior margin of dorsal mesosome with blunt angle in P. microsomaticus, but with acute angle in P. pseudhirundo sp. nov. (Fig. 46).

The sclerotized median section of the hyaline margin was not mentioned by either Tandan (1955) or Clay \& Hopkins (1960); however, in specimens of P. microsomaticus we have examined, the sclerotized median section is evident. Presumably, this character also occurs in other species of Philopterus from hirundinid hosts, but this has to be verified.

\section{Etymology}

The specific name is derived from the type host genus.

\section{Material examined}

\section{Holotype}

NO LOCALITY • đ; South Africa?; 5 Jun. 1950; [F.] Zumpt leg.; ex Pseudhirundo griseopyga (as Hirundo griseopygia); "S-125, I.N. 1373/26”; MFN.

\section{Paratype}

NO LOCALITY • 1 q; same collection data as for holotype; MFN.

\section{Type host}

Pseudhirundo griseopyga Sundevall, 1850 - gray-rumped swallow (Hirundinidae).

\section{Description}

Head shape and chaetotaxy as in Fig. 45, preantennal area narrow. Hyaline margin wide, extending laterally beyond marginal carina, deeply concave medianly; weak sclerotization in mid-section. Dorsal anterior plate elongated, shape as in Fig. 45. Ventral anterior plate small, anterior margin deeply concave. Coni small, blunt, directed laterally. Gular plate short, broad. Thoracic and abdominal segments as in Figs 43-44. Measurements as in Table 6.

\section{Male}

Thoracic and abdominal chaetotaxy as in Fig. 43 and Tables 2-4. Medianly continuous sternal plates present on segments V-VI, lateral accessory plates present on segments II-IV. Basal apodeme slender (Figs 46-47), widening markedly in distal end. Mesosome as in Fig. 47, with 3 microsetae on each side. Parameres short, blunt (Figs 46-47), with $p s t 1-2$ apical.

\section{Female}

Leg II on both sides of the only examined female missing or distorted, not illustrated. Thoracic and abdominal chaetotaxy as in Fig. 44 and Tables 2-4. Central sternal plates absent, lateral accessory plates present on segments III-VI. Subgenital plate and vulval margin as in Fig. 48; chaetotaxy as in Fig. 48 and Table 3. Lateral sclerotizations of vulval area extended to vulval margin. Subvulval plates elongated triangular. 


\section{Remarks}

The collection locality is not given on the slide, but the host is restricted to Africa (Turner \& Rose 1994), and Zumpt's collections are otherwise mainly from South Africa (Ledger 1980).

Conci (1941) described the genus Cypseloecus for the Philopterus species on swallows (Hirundinidae) and swifts ("Cypseli" = Apodiformes); however no Philopterus complex lice occur on swifts, and the name is thus a misnomer. This erroneous host range may be a result of earlier authors believing
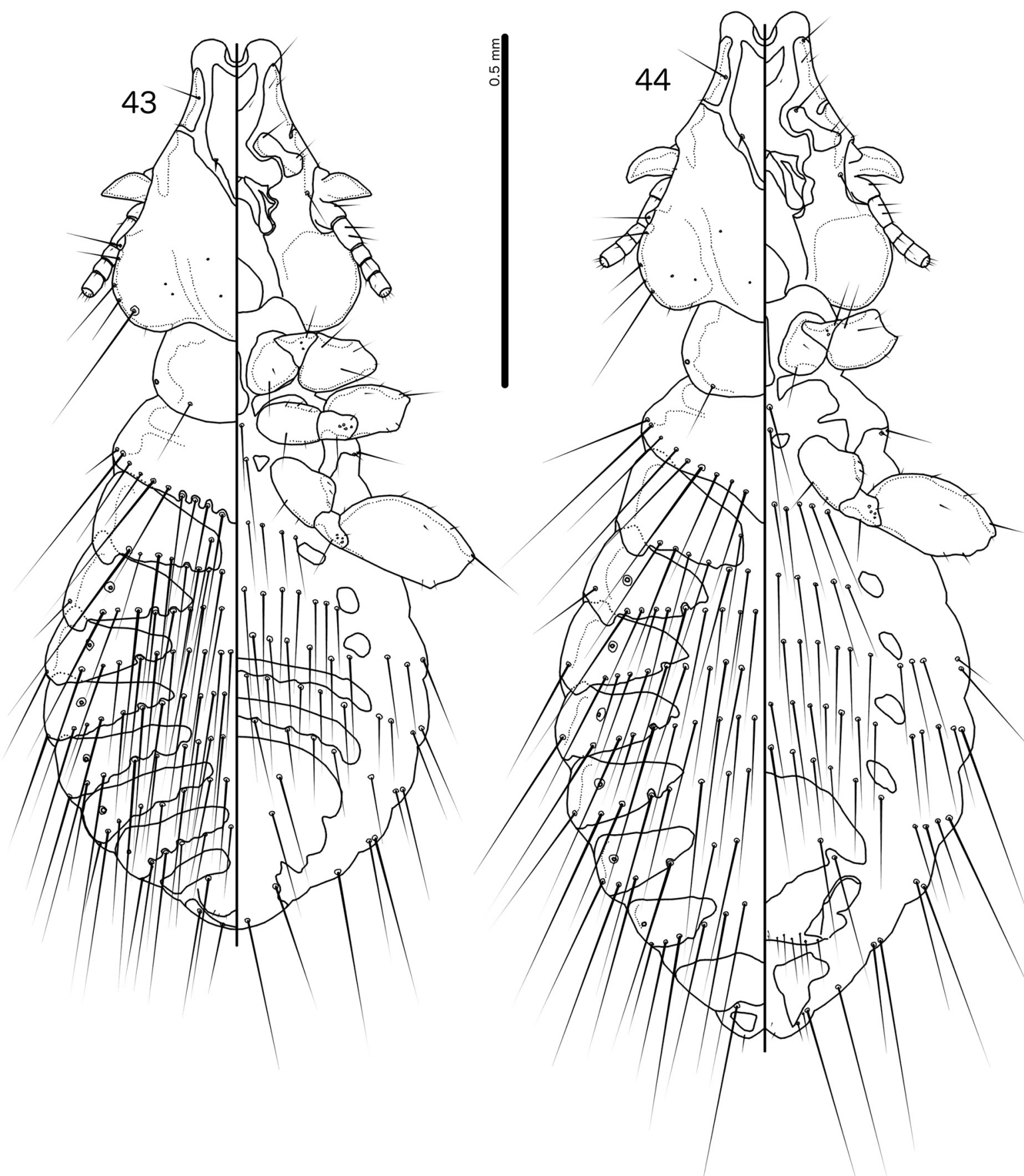

Figs 43-44. Philopterus pseudhirundo sp. nov. ex Pseudhirundo griseopyga Sundevall, 1850. 43. Male habitus, dorsal and ventral views. 44. Female habitus, dorsal and ventral views. 


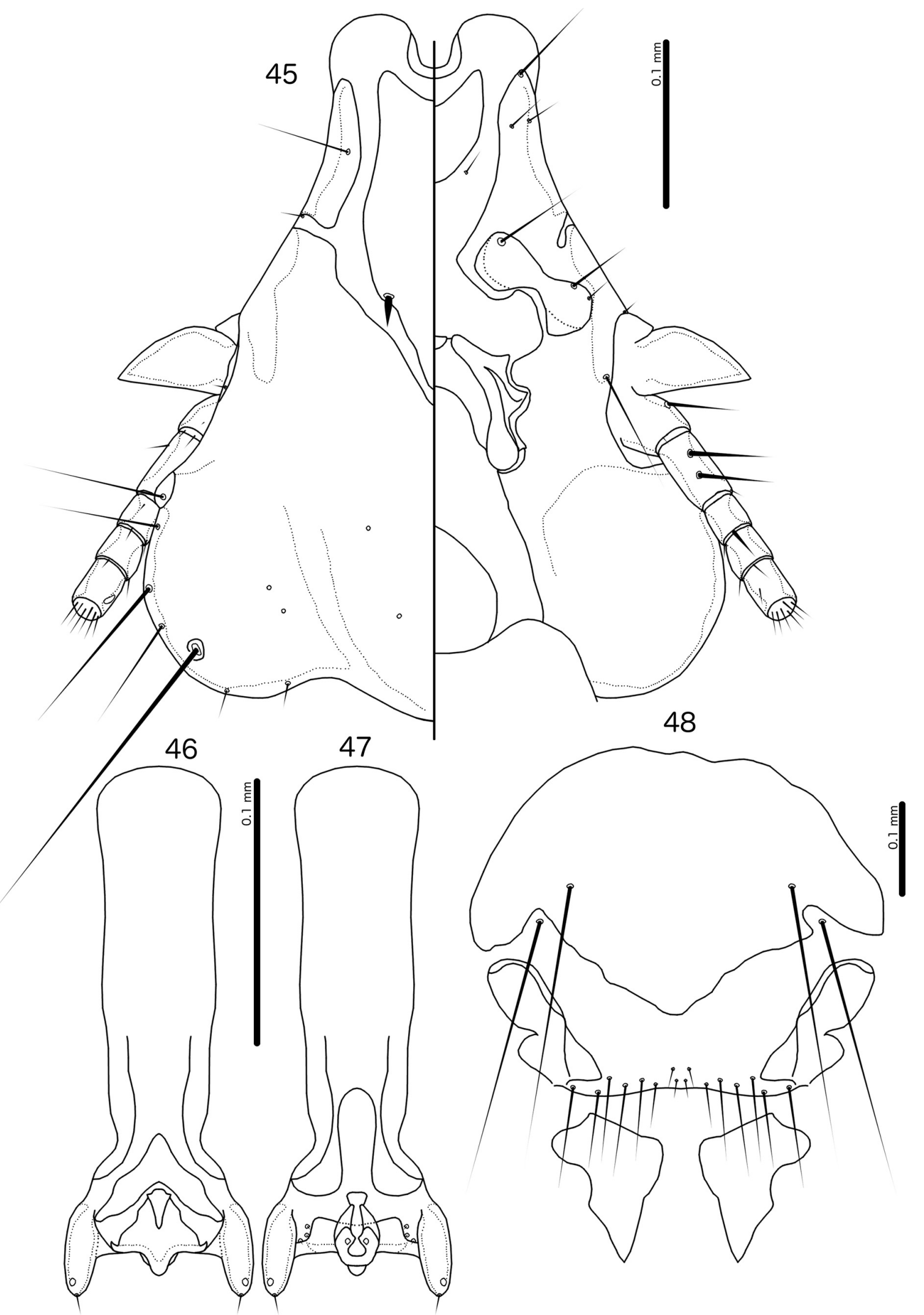

Figs 45-48. Philopterus pseudhirundo sp. nov. ex Pseudhirundo griseopyga Sundevall, 1850. 45. Male head, dorsal and ventral views. 46. Male genitalia, dorsal view. 47. Male genitalia, ventral view. 48. Female subgenital plate, vulval margin, and subvulval plates, ventral view. 
Pediculus hirundinis Schrank, 1803 (= Philopterus hirundinis (Schrank, 1803)) to be the same as Pediculus hirundinis Linnaeus, 1758 (= Dennyus hirundinis (Linnaeus, 1758)). Clay \& Hopkins (1950, 1960) showed that these names refer to different species, of which only the latter occurs on swifts. To date, nine species of Philopterus have been described from swallows (Table 7), all of which fall into the "Cypseloecus" group; if the genus Cypseloecus Conci, 1941 is resurrected, all the species listed here should be included in that genus based on their descriptions and published illustrations.

Hopkins \& Clay (1952), Price et al. (2003), and Mey (2004) considered Cypseloecus inseparable from Philopterus. Mey (2004) stated that the only notable character of this group is the bilobed state of the hyaline margin. We here describe a new species of Philopterus from a swallow, P. pseudhirundo sp. nov. This species exhibits several characteristics that seem to indicate that the Philopterus from swallows may be more different from Philopterus s. str. than previously believed. However, the relationships within Philopterus s. lat. are poorly known, and it is not clear which morphological characters are useful for the delimitation of groups within Philopterus s. lat.

The most distinctive character of the "Cypseloecus" group is the preantennal area. Compared to most other species of Philopterus, the preantennal area is narrow and elongated in "Cypseloecus," with a deeply concave frons and distinctly bilobed hyaline margin. As can be seen in the species of Philopterus described here, the shape of the preantennal area and the hyaline margin vary greatly between different species in the genus (cf., e.g., Figs 3, 9, 39). In most of the Philopterus from corvid hosts (including the type species, P. ocellatus; see Price \& Hellenthal 1998), the frons is more or less flat, convex, or only slightly concave. Even in species of Philopterus where the frons is concave (e.g., Fig. 3), the lateral parts of the hyaline margin do not form distinct, narrow lobes as in "Cypseloecus".

In P. pseudhirundo sp. nov., the central part of the hyaline margin is sclerotized (Fig. 45), which makes the head superficially resemble that of many species of Philopteroides Mey, 2004. However, this character is not illustrated or mentioned in the descriptions of any other species in "Cypseloecus." We have examined some specimens of P. microsomaticus at the Museum of Natural History, University of Wroclaw, Poland. These all have a median sclerotization similar to that of P. pseudhirundo sp. nov. Presumably, this sclerotization occurs in other species of "Cypseloecus" as well, but we have not examined any of them. No other species of Philopterus from other host families have this sclerotization, but it occurs in many other genera in the Philopterus complex (Mey 2004).

The male genitalia are also distinct in "Cypseloecus," with a rather flat distal margin of the mesosome and somewhat flaring parameres (Figs 45-46). This is unlike the genitalia of most other species described here, which have a more rounded distal margin of the mesosome and more convergent parameres (e.g., Figs 22-23). However, the type species of Philopterus, and most other species from corvid hosts, have genitalia that are more similar to those of "Cypseloecus" than to most of the other species described here. Moreover, some species of Philopterus on non-hirundinid hosts have genitalia that are intermediate between the two types (e.g., P. stansburyensis sp. nov.; Figs 34-35). Too little is known about the more detailed structure of the mesosome and other parts of the genitalia in the Philopterus complex to make a more detailed comparison.

In our opinion, these differences are not sufficient, based on our current knowledge, to recognize Cypseloecus as a distinct genus within the Philopterus complex, but are perhaps sufficient to recognize it as a subgenus within Philopterus. Potentially, at least three groups are involved: Philopterus s. str. from corvid hosts, with simple hyaline margin, typically short preantennal areas, and splayed male genitalia; "Cypseloecus" from hirundinid hosts, with a deeply bilobed hyaline margin with median sclerotization, slender and elongated preantennal area, and splayed genitalia; and Philopterus s. lat. (=? Docophorulus Eichler, 1944) from other hosts, with an intermediate hyaline margin, typically short preantennal areas, 
Table 7. Checklist of the known distribution of species of the genus Philopterus Nitzsch, 1818 on swallows (Hirundinidae). Type host species are indicated by an asterisk (*).

\begin{tabular}{|c|c|c|}
\hline Louse species & Host species & Remark \\
\hline Philopterus breviformis (Kellogg \& Kuwana, 1902) & *Progne modesta Gould, 1839 & 1 \\
\hline Philopterus dathei (Eichler in Niethammer, 1956) & *Tachycineta albiventer (Boddaert, 1783) & \\
\hline Philopterus diasi Tendeiro, 1958 & *Hirundo smithii smithii Leach \& Koenig, 1818 & 2 \\
\hline Philopterus domesticus (Kellogg, 1896) & *Progne subis (Linnaeus, 1758) & \\
\hline \multirow[t]{3}{*}{ Philopterus excisus Nitzsch, 1818} & *Delichon urbicum (Linnaeus, 1758) & 3 \\
\hline & Petrochelidon spilodera (Sundevall, 1815) & 4 \\
\hline & Riparia riparia (Linnaeus, 1758) & 5 \\
\hline \multirow[t]{2}{*}{ Philopterus major (Kellogg, 1896) } & *Petrochelidon pyrrhonota (Vieillot, 1817) & 6 \\
\hline & Tachycineta bicolor (Vieillot, 1808) & \\
\hline \multirow[t]{3}{*}{ Philopterus microsomaticus Tandan, 1955} & Cecropsis abyssinica (Guérin-Méneville, 1843) & 7 \\
\hline & Hirundo neoxena Gould, 1842 & 8 \\
\hline & *Hirundo rustica rustica Linnaeus, 1758 & 9 \\
\hline Philopterus pseudhirundo sp. nov. & *Pseudhirundo griseopyga Sundevall, 1850 & \\
\hline \multirow[t]{2}{*}{ Philopterus tropicalis Carriker, 1956} & Stelgidopteryx ruficollis (Vieillot, 1817) & 10 \\
\hline & *Stelgidopteryx serripennis (Audubon, 1838) & \\
\hline \multirow[t]{4}{*}{ Philopterus sp. } & Progne chalybea (Gmelin, 1789) & 11 \\
\hline & Progne dominicensis (Gmelin, 1789) & 11 \\
\hline & Progne tapera fusca (Vieillot, 1817) & 11 \\
\hline & Progne tapera tapera (Linnaeus, 1766) & 11 \\
\hline
\end{tabular}

Remarks:

1) Kellogg \& Kuwana (1902) reported this species from two non-hirundinid hosts from the Galápagos Islands. These records are most probably the result of human contamination, as discussed by Palma (1994) and Palma \& Peck (2013). A lectotype of this species was designated by Palma \& Peck (2013).

2) Ledger (1980) considered this species a synonym of $P$. microsomaticus based on similarities in measurements. Price et al. (2003) listed it as a valid species.

3) Redescribed and partially illustrated by Clay \& Hopkins (1960). Additional illustrations in Tandan (1955).

4) Złotorzycka et al. (1999).

5) Balát (1966).

6) Price et al. (2003) listed both hosts as type hosts, thus overlooking that Carriker (1957) selected a lectotype and designated Petrochelidon pyrrhonota as the type host of $P$. major. No illustration of this species has been published, and the description is very short and unhelpful. This species urgently needs redescription.

7) Ledger (1980).

8) Palma \& Barker (1996).

9) Records of P. excisus from Hirundo rustica have here tentatively been interpreted as P. microsomaticus; however, none of this material has been examined for this study, and both P. excisus and P. microsomaticus may occur on H. rustica in different parts of the range.

10) Clayton et al. (1992).

11) Carriker (1956).

and convergent parameres. Most likely, the morphological variation in this latter group is sufficient to recognize further subgeneric or generic groups, some of which may not be recognizable based on published illustrations and descriptions. We do not propose any taxonomic changes at the genus level here, but note that a more thorough revision of Philopterus is needed. Such a revision should, in our opinion, include a consideration of resurrecting Cypseloecus as at least a subgenus within Philopterus. 


\section{Discussion}

With the eight species described here, the numbers of known species in the Philopterus complex and the genus Philopterus (including Cypseloecus) are 224 and 193, respectively. All species of the complex described since the publication of the checklist in Price et al. (2003) are listed in Table 8. However, the number of species that can reliably be identified from published descriptions and illustrations is far lower. In general, somatic and setal characters appear to be rather uniform in Philopterus. For instance, all species described here have setal rows on abdominal segments II-VII in both sexes, but the number of setae typically overlaps between species. This suggests that these may be useful to separate closely related species, but less useful to establish relationships between distantly related species. Similarly, the head chaetotaxy is essentially the same in all species described here and varies little within the Philopterus complex in general, with the exception of some preantennal setae. Moreover, apart from differences in the development of the ventral and marginal carinae (Mey 2004), the head structure shows less variation within the Philopterus complex than in, e.g., the Brueelia, Oxylipeurus, and Degeeriella complexes.

This relative homogeneity in setal and somatic characters means that the characters that are usually illustrated for species of Philopterus in the published literature (e.g., outlines of heads, dorsal anterior plates, subgenital plates, etc.) are of little use to determine which species are closely related. In contrast, the differences in the structure and complexity of the male genitalia are evident from the species described here (cf., e.g., P. afropari sp. nov. (Figs 16-17) and P. coriaceus sp. nov. (Figs 40-41)). The size, shape, and structure of the mesosome, the location and presence or absence of mesosomal setae, the length and shape of the parameres, and the overall structure of the basal apodeme all vary between the species described here. In some cases, the structures seen in one species appear to have no counterpart in other species (e.g., the ventral plates near the anterior end of the mesosome in P. coriaceus sp. nov.; Fig. 41). This variation suggests that male genitalia may be the key to assessing the relationships among species of Philopterus and in evaluating whether or not this genus is monophyletic. Many of the details of the male genitalia illustrated here (e.g., mesosomal sensilla) are generally only visible at high magnifications using oil immersion and phase contrast. Limitations in microscope technology may explain why male genitalia have rarely been illustrated in sufficient detail to be of much use in the past. Notably, many of the characters used to establish species groups within Philopterus by Złotorzycka \& Lucińska (1975, 1976) are from the male genitalia.

Moreover, it is presently difficult to assess patterns of host associations in Philopterus. Mey (2004) summarized the known host distributions of the Philopterus complex genera. Some of the gaps in his summary have now been filled (e.g., Tyranniphilopterus on Polioptilidae (Cicchino 2007); Philopteroides on Rhipiduridae (Valim \& Palma 2013)), and the discovery of the new genus Vinceopterus Gustafsson et al., 2019 on trogons fell outside the framework of his summary. Nevertheless, few species of Philopterus have been described since 2004 (Table 8), and the outline published by Mey (2004) largely holds true today.

Mey's summary suggests that Philopterus as currently defined parasitizes a wide range of hosts representing most of the major radiations of passeriforms. However, the genus is not known from any suboscine hosts, and it appears to be largely replaced by Tyranniphilopterus in many primarily Neotropical host families and by Philopteroides in many exclusively Old World tropical host families; the correct placement of some poorly known Philopterus species from the Australo-Papuan region may also be questionable. The bulk of the species in Philopterus are thus found on host families that occur in the Holarctic. Notably, both Philopteroides and Philopterus are distributed across the two main radiations of Passeriformes, Corvides and Passerida, which may hint at a rich history of host switching in the evolution of the Philopterus complex. However, determining any such patterns of host switching or co-evolution will require a thorough revision of Philopterus. Useful characters to identify groups 


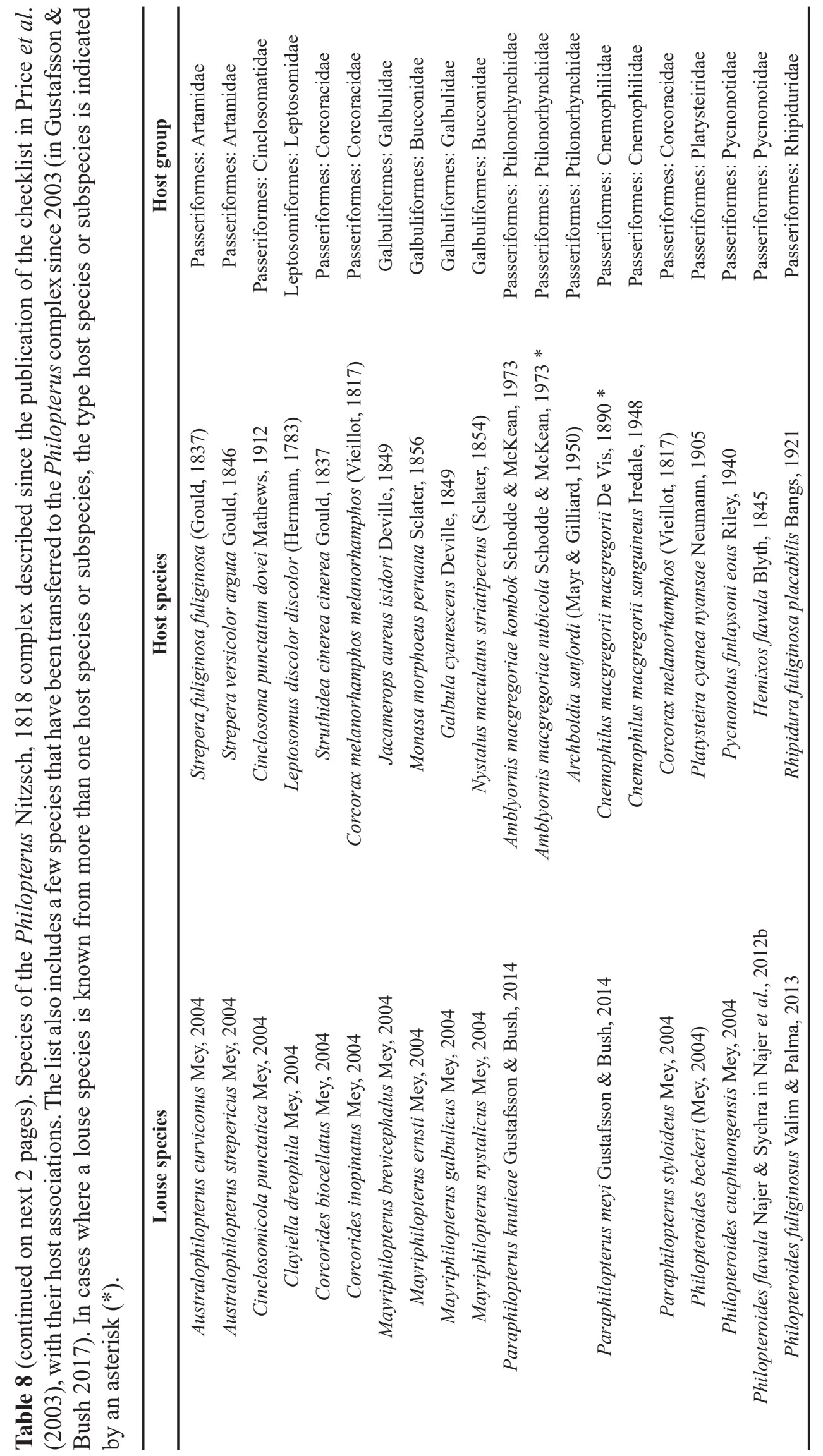




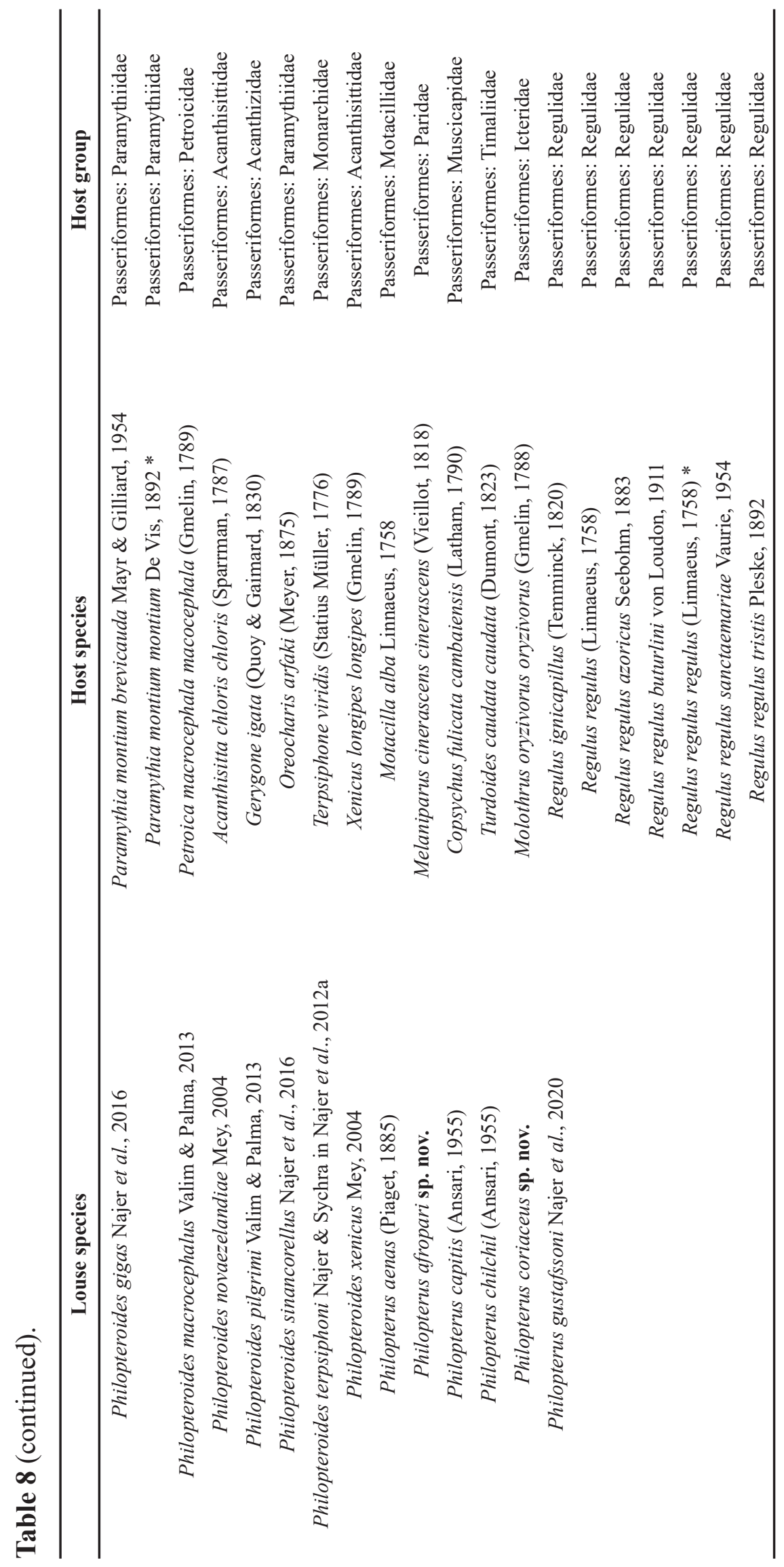




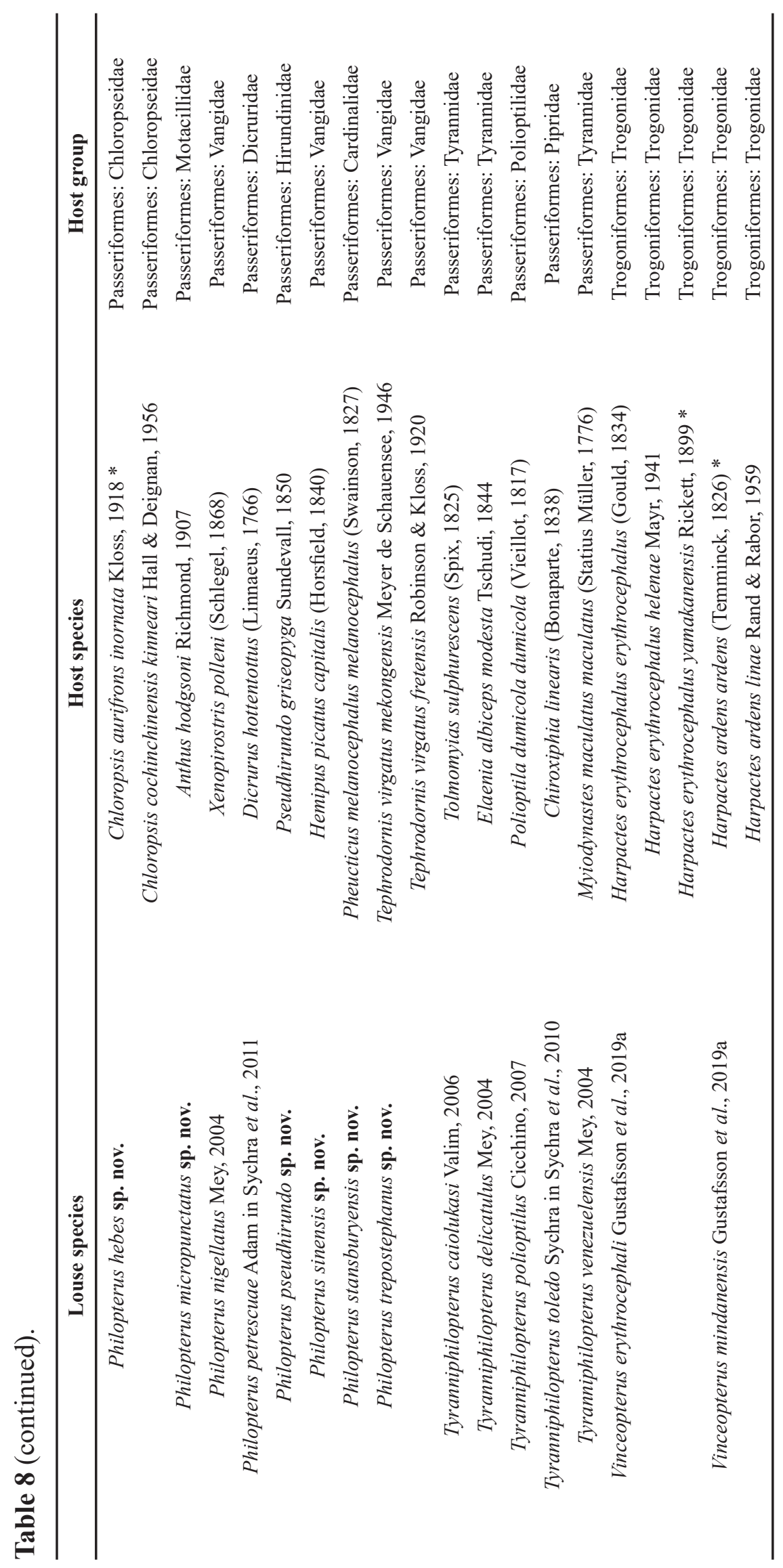


within Philopterus will need to be detected and evaluated before specimens used either for molecular or morphological analysis can be properly identified. The male genitalia appear to constitute an excellent source for such characters, but these need to be better described for almost all known species in the Philopterus complex.

\section{Acknowledgements}

This research was funded by grant 36/07 1.4 from the Swedish Taxonomic Initiative, grant NSFDEB-1050706, NSF 1926738, the Introduction of Full-Time High-Level Talent Fund of the Guangdong Academy of Sciences grant 2018GDASCX-0809, GDAS Special Project of Science and Technology Development grants 2017GDASCX-0107 and 2018GDASCX-0107, and GIABR-GJRC201701, and the Pearl River Talent Recruitment Program of Guangdong Province, grant 2019QN01N968. These agencies had no influence in the design or execution of this study, and we declare no conflict of interest. Two anonymous reviewers provided helpful comments during the review of this manuscript, for which we are very grateful.

\section{References}

Ansari R.A.M. 1955. Studies on ischnoceran Mallophaga parasitic on Turdidae (sens. lat.). Pakistan Journal of Health 5 (2): 47-76.

Ansari R.A.M. 1956. Some new ischnoceran Mallophaga in the Zoological Survey Department, Karachi. Pakistan Journal of Scientific Research 8: 10-22.

Ansari R.A.M. 1958. Studies on ischnoceran Mallophaga infesting birds in the Panjab. The Indian Journal of Entomology 20: 77-103.

Balát F. 1955. Mallophaga aus dem Nationalpark in der Hohen Tatra. Zoologické a Entomologické Listy 4: 389-398.

Balát F. 1966. Federlinge tschechoslowakischer Uferschwalben. Angewandte Parasitologie 7: 20-30.

Carriker M.A. Jr. 1956. Report on a collection of Mallophaga, largely Mexican (Part II). The Florida Entomologist 39: 19-43, 69-84, 119-132. https://doi.org/10.2307/3492427

Cicchino A.C. 1990. Contribución al conocimiento de los malófagos argentinos. XX. Primera adición a la revisión preliminar de las especies del género Brueelia Kéler, 1936 (Mallophaga: Philopteridae) parásitas de Icterinae (Aves: Passeriformes: Emberizidae). Spheniscus 8: 21-26.

Cicchino A.C. 2004. Adición a la revisión de las especies del género Brueelia Kéler, 1936 (Phthiraptera: Philopteridae) parásitas de Icterinae. Las especies parásitas del género Agelaius Vieillot, 1816 (Aves: Passeriformes: Fringillidae). Boletin Museo Nacional de Historia Natural del Paraguay 15: 66-81.

Cicchino A.C. 2007. Tyranniphilopterus polioptilus new species (Phthiraptera: Ischnocera: Philopteridae) parasitic on the Masked Gnatcatcher, Polioptila dumicola (Passeriformes: Polioptilidae) in Argentina. Zootaxa 1547 (1): 43-50. https://doi.org/10.11646/zootaxa.1547.1.4

Cicchino A.C. \& Castro D.C. 1996. Revisión preliminar de las especies del género Brueelia Kéler, 1936 (Phthiraptera, Philopteridae) parásitas de Icterinae (Aves, Passeriformes, Fringillidae). Graellsia 52: 3-30. https://doi.org/10.3989/graellsia.1996.v52.i0.373

Clay T. 1951. An introduction to a classification of the avian Ischnocera (Mallophaga): Part I. Transactions of the Entomological Society of London 102: 171-194.

https://doi.org/10.1111/j.1365-2311.1951.tb00746.x 
Clay T. \& Hopkins G.H.E. 1950. The early literature on Mallophaga. Part I. 1758-62. Bulletin of the British Museum (Natural History), Entomology 1: 221-271. https://doi.org/10.5962/bhl.part.27230

Clay T. \& Hopkins G.H.E. 1960. The early literature on Mallophaga (Part IV, 1787-1818). Bulletin of the British Museum (Natural History), Entomology 9: 1-61. https://doi.org/10.5962/bhl.part.27551

Clayton D.H., Gregory R.D. \& Price R.D. 1992. Comparative ecology of Neotropical bird lice (Insecta: Phthiraptera). Journal of Animal Ecology 61: 781-795. https://doi.org/10.2307/5631

Clements J.F., Schulenberg T.S., Iliff M.J., Roberson D., Fredericks T.A., Sullivan B.L. \& Wood C.L. 2019. The eBird/Clements Checklist of Birds of the World. 2019 version.

Available from: http://www.birds.cornell.edu/clementschecklist/download/ [accessed 23 Sep. 2019].

Conci C. 1941. Nuovi generi di mallofagi. Bollettino della Società entomologica italiana 73: 126-127.

Eichler W. 1944. Notulae Mallophagologicae. XI. Acht neue Gattungen der Nirmi und Docophori. Stettiner entomologische Zeitung 105: 80-82.

Eichler W. 1953. Von Alexander Koenig gesammelte Federlinge I. Von Singvögeln und Spechten. Bonner zoologische Beiträge 3/4: 333-343.

Emerson K.C. 1960. Notes on the Osborn Mallophaga types. Proceedings of the Biological Society of Washington 73: 155-166.

Fedorenko I.A. \& Vasjukova T.T. 1985. A new species of the genus Philopterus (Mallophaga, Philopteridae) from Parus cinetus of Yakutia. Vestnik Zoologii 2: 22-3. [In Russian]

Gustafsson D.R. \& Bush S.E. 2014. Two new species of Paraphilopterus Mey, 2004 (Phthiraptera: Ischnocera: Philopteridae) from New Guinean bowerbirds (Passeriformes: Ptilonorhynchidae) and satinbirds (Passeriformes: Cnemophilidae). Zootaxa 3873 (2): 155-164.

https://doi.org/10.11646/zootaxa.3873.2.3

Gustafsson D.R. \& Bush S.E. 2017. Morphological revision of the hyperdiverse Brueelia-complex (Insecta: Phthiraptera: Ischnocera: Philopteridae) with new taxa, checklists and generic key. Zootaxa 4313 (1): 1-443. https://doi.org/10.11646/zootaxa.4313.1.1

Gustafsson D.R., Lei L., Chu X., Zou F. \& Bush S.E. 2019. New genus and two new species of chewing lice from southeast Asian trogons (Aves: Trogoniformes), with a revised key to the Philopterus-complex. Acta Parasitologica 64: 86-102. https://doi.org/10.2478/s11686-018-00011-x

Hahn D.C., Price R.D. \& Osenton P.C. 2000. Use of lice to identify cowbird hosts. The Auk 117: 943651. https://doi.org/10.1093/auk/117.4.943

Hopkins G.H. \& Clay T. 1952. A Check List of the Genera and Species of Mallophaga. British Museum (Natural History), London. https://doi.org/10.5962/bhl.title.118844

Johnson K.P., Shreve S.M. \& Smith V.S. 2012. Repeated adaptive divergence of microhabitat specialization in avian feather lice. BMC Biology 10: e52. https://doi.org/10.1186/1741-7007-10-52

Kellogg V.L. \& Kuwana S.I. 1902. Papers from the Hopkins Stanford Galapagos Expedition, 18981899. X. Entomological results (8). Mallophaga from birds. Proceedings of the Washington Academy of Sciences 4: 457-499.

Ledger J.A. 1980. Phthiraptera (Insecta). The Arthropod Parasites of Vertebrates in Africa South of the Sahara, Volume IV. Publications of the South African Institute for Medical Research 56. South African Institute for Medical Research, Johannesburg. 
Mey E. 1988. Zur Taxonomie der auf Meisen (Paridae) parasitierenden Docophorulus-Arten (Insecta, Phthiraptera, Philopteridae). Rudolstädter naturhistorische Schriften 1: 71-77.

Mey E. 1994. Beziehungen zwischen Larvenmorphologie und Systematik der Adulti bei den VogelIschnozeren (Insecta, Phthiraptera, Ischnocera). Mitteilungen aus dem zoologischen Museum in Berlin 70 (1): 3-84. https://doi.org/10.1002/mmnz.19940700102

Mey E. 2004. Zur Taxonomie, Verbreitung und parasitophyletischer Evidenz des Philopterus-Komplexes (Insecta, Phthiraptera, Ischnocera). Ornithologischer Anzieger 43: 149-203.

Najer T., Sychra O., Literák I., Procházka P., Čapek M. \& Koubek P. 2012a. Chewing lice (Phthiraptera) from wild birds in Senegal, with descriptions of three new species of the genera Brueelia and Philopteroides. Acta Parasitologica 57: 90-98. https://doi.org/10.2478/s11686-012-0005-x

Najer T., Sychra O., Hung N.M., Čapek M., Podzemny P. \& Literak I. 2012b. New species and new records of chewing lice (Phthiraptera: Amblycera and Ischnocera) from bulbuls (Passeriformes: Pycnonotidae) in Vietnam. Zootaxa 3357 (1): 37-48. https://doi.org/10.11646/zootaxa.3357.1.3

Najer T., Gustafsson D.R. \& Sychra O. 2016. Two new species of Philopteroides (Phthiraptera: Ischnocera: Philopteridae) of the beckeri species-group, from New Guinean painted berrypeckers (Aves: Passeriformes: Paramythiidae). Zootaxa 4139 (4): 527-541. https://doi.org/10.11646/zootaxa.4139.4.5

Najer T., Papousek I., Adam C., Trnka A., Quach V.T., Nguyen C.N., Figura R., Literak I. \& Sychra O. 2020a. New records of Philopterus (Ischnocera: Philopteridae) from Acrocephalidae and Locustellidae, with description of one new species from Regulidae. European Journal of Taxonomy 632: 1-37.

https://doi.org/10.5852/ejt.2020.632

Najer T., Papousek I., Sychra O., Sweet A.D. \& Johnson K.P. 2020b. Combining nuclear and mitochondrial loci provides phylogenetic information in the Philopterus complex of lice (Psocodea: Ischnocera: Philopteridae). Journal of Medical Entomology 58: 252-260.

https://doi.org/10.1093/jme/tjaa166

Naz S., Najer T. \& Gustafsson D.R. 2020. An annotated list of the species of lice (Insecta: Phthiraptera) described by Mohammad A.-R. Ansari. Zootaxa 4809 (3): 401-448.

https://doi.org/10.11646/zootaxa.4809.3.1

Neumann L.G. 1906. Notes sur les mallophages. Bulletin de Société zoologique de France 31: 54-60. https://doi.org/10.5962/bhl.part.18334

Nitzsch C. 1818. Die Familien und Gattungen der Thierinsekten (Insecta Epizoica); als Prodromus einer Naturgeschichte derselben. Magazine der Entomologie 3: 261-316.

Osborn H. 1896. Insects Affecting Domestic Animals: an Account of the Species of Importance in North America, with Mention of Related Forms Occurring on Other Animals. Chapter V. Suborder Mallophaga. U. S. Department of Agriculture, Division of Entomology, Washington D.C.

https://doi.org/10.5962/bhl.title.64990

Palma R.L. 1994. The identity of Nirmus obtusus and other Quadraceps species (Phthiraptera: Philopteridae) from Clipperton Island and the Galápagos Islands. Journal of the Royal Society of New Zealand 24: 267-276. https://doi.org/10.1080/03014223.1994.9517471

Palma R.L. \& Barker S.C. 1996. Phthiraptera. In: Wells A. (ed.) Zoological Catalogue of Australia. 26. Psocoptera, Phthiraptera, Thysanoptera: 81-247, 333-361 (app. I-IV), 373-396 (index). CSIRO Publishing, Melbourne. 
Palma R.L. \& Peck S.B. 2013. An annotated checklist of parasitic lice (Insecta: Phthiraptera) from the Galápagos Islands. Zootaxa 3627 (1): 1-87. https://doi.org/10.11646/zootaxa.3627.1.1

Price R.D. \& Hellenthal R.A. 1998. Taxonomy of Philopterus (Phthiraptera: Philopteridae) from the Corvidae (Passeriformes), with descriptions of nine new species. Annals of the Entomological Society of America 91: 782-799.

Price R.D., Hellenthal R.A. \& Palma R.L. 2003. World checklist of chewing lice with host associations and keys to families and genera. In: Price R.D., Hellenthal R.A., Palma R.L., Johnson K.P. \& Clayton D.H. (eds) The Chewing Lice: World Checklist and Biological Overview: 1-501. Illinois Natural History Survey Special Publication 24.

Robson C. 2006. A Field Guide to the Birds of Thailand. Asia Books Co. Ltd, Bangkok.

Sychra O., Najer T., Kounek F., Capek M. \& Literak I. 2010. Chewing lice (Phthiraptera) on manakins (Passeriformes: Pipridae) from Costa Rica, with description of a new species of the genus Tyranniphilopterus (Phthiraptera: Philopteridae). Parasitology Research 106: 925-931. https://doi.org/10.1007/s00436-010-1768-3

Sychra O., Palma R.L., Saxena A.K., Ahmad A., Bansal N. \& Adam C. 2011. Chewing lice of the genus Philopterus (Phthiraptera: Philopteridae) from drongos (Passeriformes: Dicruridae). Zootaxa 2868 (1): 51-61. https://doi.org/10.11646/zootaxa.2868.1.2

Tandan B.K. 1955. Mallophagan parasites from Indian birds. Part IV. Species belonging to the genera Philopterus, Capraiella and Pectinopygus (Superfamily Ischnocera). Annals and Magazine of Natural History, Series 128 (90): 417-433. https://doi.org/10.1080/00222935508656069

Tendeiro J. 1962. Études sur les mallophages. Observations sur des Ischnocera africains, avec descriptions de 12 espèces et 2 sous-espèces nouvelles. Boletim cultural da Guiné Portuguesa 68: 669-704.

Turner A. \& Rose C. 1994. Swallows and Martins of the World. Christopher Helm (Publishers) Ltd., London.

Uchida S. 1948. Studies on the biting-lice (Mallophaga) of Japan and adjacent territories (suborder Ischnocera Pt. I). Japanese Medical Journal 1: 303-326. https://doi.org/10.7883/yoken1948.1.303

Valim M.P. 2006. Tyranniphilopterus caiolukasi sp. n. (Phthiraptera: Philopteridae) from the yellowolive flycatcher (Aves: Tyrannidae), with observations on gut content. Lundiana 7: 55-58.

Valim M.P. \& Palma R.L. 2012. Redescription of two species and description of three new species of the louse genus Bizarrifrons Eichler, 1938 (Phthiraptera: Ischnocera: Philopteridae). Zootaxa 3273 (1): 28-50. https://doi.org/10.11646/zootaxa.3273.1.2

Valim M.P. \& Palma R.L. 2013. Three new species of the genus Philopteroides Mey, 2004 (Phthiraptera, Ischnocera, Philopteridae) from New Zealand. ZooKeys 297: 71-89.

https://doi.org/10.3897/zookeys.297.5118

Złotorzycka J. 1964. Mallophaga parasitizing Passeriformes and Pici III. Philopterinae. Acta Parasitologica Polonica 12: 401-435.

Złotorzycka J. \& Eichler W. 1984. Notulae Mallophagologicae. XIV. Prunellides annae nov. gen. et spec. von Prunella modularis. Angewandte Parasitologie 25: 219-221.

Złotorzycka J. \& Lucińska A. 1975. Systematische Studien an den europäischen Arten der Gattungen Philopterus und Docophorulus (Mallophaga, Philopteridae). I. Teil. Die Gattung Philopterus Nitzsch. Polskie Pismo Entomologiczne 45: 547-563. 
Złotorzycka J. \& Lucińska A. 1976. Systematische Studien an den europäischen Arten der Gattungen Philopterus und Docophorulus (Mallophaga, Philopteridae). II. Teil. Die Gattung Docophorus Eichler. Polskie Pismo Entomologiczne 46: 261-317.

Złotorzycka J., Modrzejewska K. \& Kopij G. 1999. A preliminary study on Mallophaga in South African birds. Polskie Pismo Entomologiczne 68: 9-21.

Manuscript received: 7 December 2020

Manuscript accepted: 18 November 2021

Published on: 4 February 2022

Topic editor: Nesrine Akkari

Desk editor: Danny Eibye-Jacobsen

Printed versions of all papers are also deposited in the libraries of the institutes that are members of the EJT consortium: Muséum national d'histoire naturelle, Paris, France; Meise Botanic Garden, Belgium; Royal Museum for Central Africa, Tervuren, Belgium; Royal Belgian Institute of Natural Sciences, Brussels, Belgium; Natural History Museum of Denmark, Copenhagen, Denmark; Naturalis Biodiversity Center, Leiden, the Netherlands; Museo Nacional de Ciencias Naturales-CSIC, Madrid, Spain; Real Jardín Botánico de Madrid CSIC, Spain; Zoological Research Museum Alexander Koenig, Bonn, Germany; National Museum, Prague, Czech Republic. 